\title{
Disentangling marine microbial networks across space
}

Ina Maria Deutschmann ${ }^{1 *}$, Erwan Delage ${ }^{2,3}$, Caterina R. Giner ${ }^{1}$, Marta Sebastián ${ }^{1}$, Julie Poulain ${ }^{4}$, Javier Arístegui ${ }^{5}$, Carlos M. Duarte ${ }^{6}$, Silvia G. Acinas ${ }^{1}$, Ramon Massana ${ }^{1}$, Josep M. Gasol ${ }^{1,7}$, Damien Eveillard $^{2,3}$, Samuel Chaffron ${ }^{2,3}$ and Ramiro Logares ${ }^{1 *}$

${ }^{1}$ Institute of Marine Sciences, CSIC, Passeig Marítim de la Barceloneta, 37-49, 08003, Barcelona, Spain

9 2Université de Nantes, CNRS UMR 6004, LS2N, F-44000, 2 rue de la Houssinière, 44322, Nantes, France

10 3Research Federation for the study of Global Ocean Systems Ecology and Evolution, FR2022 / Tara Oceans GOSEE, 3 rue Michel11 Ange, 75016 Paris, France

12 4Génomique Métabolique, Genoscope, Institut François Jacob, CEA, CNRS, Univ Evry, Université Paris-Saclay, Evry, France

13 Instituto de Oceanografía y Cambio Global, IOCAG, Universidad de Las Palmas de Gran Canaria, ULPGC, Gran Canaria, Spain

$14{ }^{6}$ King Abdullah University of Science and Technology (KAUST), Red Sea Research Center (RSRC), Thuwal, Saudi Arabia

$15{ }^{7}$ Center for Marine Ecosystems Research, School of Sciences, Edith Cowan University, Joondalup, WA Australia

*Corresponding authors: Ina Maria Deutschmann (ina.m.deutschmann@gmail.com) and Ramiro Logares (ramiro.logares@icm.csic.es)

26 Short title: Marine microbial networks across space 


\section{ABSTRACT}

28 Although microbial interactions underpin ocean ecosystem functions, they remain barely known.

29 Different studies have analyzed microbial interactions using static association networks based on

30 omics-data. However, microbial associations are dynamic and can change across physicochemical

31 gradients and spatial scales, which needs to be considered to understand the ocean ecosystem better.

32 We explored associations between archaea, bacteria, and picoeukaryotes along the water column from

33 the surface to the deep ocean across the northern subtropical to the southern temperate ocean and the

34 Mediterranean Sea by defining sample-specific subnetworks. Quantifying spatial association

35 recurrence, we found the lowest fraction of global associations in the bathypelagic zone, while

36 associations endemic of certain regions increased with depth. Overall, our results highlight the need to

37 study the dynamic nature of plankton networks and our approach represents a step forward towards a

38 better comprehension of the biogeography of microbial interactions across ocean regions and depth

39 layers. 


\section{INTRODUCTION}

41 Microorganisms play fundamental roles in ecosystem functioning (DeLong, 2009; Krabberød et al.,

42 2017) and ocean biogeochemical cycling (Falkowski et al., 2008). The main processes shaping

43 microbial community composition are selection, dispersal, and drift (Vellend, 2020). Selection exerted

44 via environmental conditions and biotic interactions are essential in structuring the ocean microbiome

45 (Logares et al., 2020), leading to heterogeneities reflecting those in the ocean environment, mainly in

46 terms of temperature, light, pressure, nutrients and salinity. In particular, global-scale studies of the

47 surface ocean reported strong associations between microbial community composition and diversity

48 with temperature (Sunagawa et al., 2015; Ibarbalz et al., 2019; Salazar et al., 2019; Logares et al.,

49 2020). Marked changes in microbial communities with ocean depth have also been reported (Cram $e t$

50 al., 2015; Parada \& Fuhrman, 2017; Mestre et al., 2018; Peoples et al., 2018; Xu et al., 2018; Giner et

$51 a l ., 2020)$, reflecting the steep vertical gradients in light, temperature, nutrients and pressure.

Prokaryotes (bacteria and archaea) and unicellular eukaryotes are fundamentally different in

53 terms of ecological roles, functional versatility, and evolutionary history (Massana \& Logares, 2013)

54 and are connected through biogeochemical and food web interaction networks (Layeghifard et al.,

55 2017; Seymour et al., 2017). Still, knowledge about these interactions remains limited despite their

56 importance to understand better microbial life in the oceans (Krabberød et al., 2017; Bjorbækmo et

$57 a l ., 2019)$. Such interactions are very difficult to resolve experimentally, mainly because most

58 microorganisms are hard to cultivate (Baldauf, 2008; Lewis et al., 2020) and synthetic laboratory

59 communities are unlikely to mirror the complexity of wild communities. However, metabarcoding

60 approaches to identify and quantify marine microbial taxa allow to infer association networks, where

61 nodes represent microorganisms and edges potential interactions.

Association networks provide a general overview of the microbial ecosystem aggregated over

63 a given period of time (Steele et al., 2011; Chow et al., 2013, 2014; Cram et al., 2015; Needham et al.,

64 2017; Parada \& Fuhrman, 2017) or through space (Lima-Mendez et al., 2015; Milici et al., 2016; 
65 Chaffron et al., 2020). Previous work characterized potential marine microbial interactions, including associations within and across depths. For example, monthly sampling allowed investigating

67 prokaryotic associations in the San Pedro Channel, off the coast of Los Angeles, California, covering

68 the water column from the surface (5 m) to the seafloor ( $890 \mathrm{~m})$ (Cram et al., 2015; Parada \& Fuhrman,

69 2017). Furthermore, a global spatial survey occurring within the TARA Oceans expedition, allowed

70 to investigate planktonic associations between a range of organismal size fractions in the epipelagic

71 zone, from pole to pole (Lima-Mendez et al., 2015; Chaffron et al., 2020). However, these studies did

72 not include the bathypelagic realm, below $1000 \mathrm{~m}$ depth, which represents the largest microbial habitat

73 in the biosphere (Arístegui et al., 2009).

A single static network determined from spatially distributed samples over the global ocean captures global, regional and local associations. Also, given that global-ocean expeditions collect samples over several months, networks could include temporal associations, yet disentangling them from spatial associations is normally complicated and not considered. Global associations may constitute the core interactome, that is, the set of microbial interactions essential for the functioning of the ocean ecosystem (Shade \& Handelsman, 2012). Core associations may be detected by constructing a single network from numerous locations and identifying the most significant associations and strongest associations (Coutinho et al., 2015). On the other hand, regional and local associations may point to interactions occurring in specific spatial areas of different sizes due to particular taxa distributions resulting from environmental selection, dispersal limitation, specific ecological niches or biotic/abiotic filtering. The fraction of regional associations may be determined

85 by excluding all samples belonging to one region and recomputing network inference with the reduced dataset (Lima-Mendez et al., 2015). Alternatively, regional networks can be built allowing to determine both, global and regional associations (Mandakovic et al., 2018) by investigating which edges networks have in common and which are unique. Such regional networks could contribute to 
90 heterogeneity, also helping to comprehend associations that are stable (i.e., two partners always

91 together) or variable (one partner able to interact with multiple partners across locations).

Regional networks, however, require a high number of samples per delineated zone, but these

93 may not be available due to logistic or budgetary limitations. Recent approaches circumvent this

94 limitation by deriving sample-specific subnetworks from a single static, i.e., all-sample network, which

95 allows quantifying association recurrence over spatiotemporal scales (Chaffron et al., 2020;

96 Deutschmann et al., 2021). Here, we adjusted this approach and used it to determine global and

97 regional associations along vertical and horizontal ocean scales, which allowed us determining the

98 biogeography of marine microbial associations. We analyzed associations between archaea, bacteria,

99 and picoeukaryotes covering the water column, from surface to deep waters, in the Mediterranean Sea

100 (hereafter MS) and five ocean basins: North and South Atlantic Ocean, North and South Pacific Ocean,

and Indian Ocean (hereafter NAO, SAO, NPO, SPO, and IO). We estimated microbial taxa abundances

using 397 globally distributed samples from the epipelagic to the bathypelagic zone in six ocean

regions (Figure 1). We separated most epipelagic samples into surface and deep-chlorophyll maximum

104 (DCM) samples. Next, we constructed a first global network comprising 5457 nodes and 31966 edges,

10530657 (95.9\%) positive and 1309 (4.1\%) negative. Then, we applied a filter strategy including the removal of environmentally-driven edges due to nutrients $\left(4.9 \% \mathrm{NO}_{3}{ }^{-}, 4.2 \% \mathrm{PO}_{4}{ }^{3-}, 2.0 \% \mathrm{SiO}_{2}\right)$, temperature $(1.9 \%)$, salinity $(0.2 \%)$, and Fluorescence $(0.01 \%)$ (Supplementary Table 1$)$. Altogether, our sample-specific network-based exploration allowed us to determine core associations in the global ocean and specific regions, analyze changes in associations and network topology with depth and regions, and to investigate the vertical connectivity of planktonic associations.

\section{RESULTS}

113 From a global static network to sample-specific subnetworks 
114 The resulting global static network contained 5448 nodes and 29118 edges, 28178 (96.8\%) positive

115 and $940(3.2 \%)$ negative. It served as the underlying structure from which we generated 397 sample-

116 specific subnetworks following three criteria. First, we required that an edge must be present in the

117 global static network. Second, an edge can only be present within a subnetwork if both microorganisms

118 associated with the edge have a sequence abundance above zero in the corresponding sample. Third,

119 microorganisms associated need to appear together (intersection) in more than $20 \%$ of the samples, in

120 which one or both appear (union) for that specific region and depth. This third condition was robust

121 since random subsets retained most associations compared with the associations obtained when using

122 all samples (Supplementary Figure 1). In addition to these three conditions, a node is present in a

123 subnetwork if it has at least one association partner. Consequently, each subnetwork is included in the

124 global static network.

\section{Spatial recurrence}

127 We determined the spatial recurrence of each association using its prevalence computed as the fraction 128 of subnetworks in which a given association was present across the 397 samples (Figure 2A) and 129 within each region-depth-layer combination (Figure 2B). The global ocean surface layer (contributing with $40 \%$ of samples) had more associations compared to the other depths (Figure 2B). Remarkably,

13114971 of $18234(82.1 \%)$ global ocean surface associations were absent from the MS. In turn, the 132 number of surface associations was similar across ocean basins (Figure 2B).

Considering the most prevalent associations (those found in over $70 \%$ of subnetworks), we

134 found that major vertical taxonomic patterns were conserved across regions: the epipelagic layers 135 (surface and DCM) and the two lower layers (meso- and bathypelagic zones) were more similar to 136 each other, respectively (Figure 3). The fraction of associations including Alphaproteobacteria was 137 moderate to high in all zones in contrast to Cyanobacteria appearing mainly, as expected, in the 138 epipelagic zone (Figure 3). The fraction of Dinoflagellata associations was moderate to high in the 
139 epipelagic zone and lower in the meso- and bathypelagic zones. While Dinoflagellata associations

140 dominated most epipelagic layers, fewer were found in the MS and SAO surface and NAO DCM

141 (Figure 3). Thaumarchaeota associations were moderate to high especially in the mesopelagic

142 (dominant in the MS), moderate in the bathypelagic, and lower in the epipelagic zone (Figure 3).

143 Another interesting pattern is the increase in associations including Gammaproteobacteria with depth

144 being higher in the meso- and bathypelagic than in the epipelagic, especially in the SAO, SPO, NPO 145 and IO.

Highly prevalent associations present across all regions are candidates to represent putative 147 core interactions in the global ocean, which are likely to perform processes crucial for ecosystem 148 functioning. We defined global associations as those appearing in more than $70 \%$ of subnetworks in 149 each region. While we found several (21-26) global associations in the epi- and mesopelagic zones, no 150 global associations were identified in the bathypelagic zone (Table 1, Supplementary Figure 2). In addition, we resolved prevalent (>50\%) and low-frequency (>20\%) associations. These three types of associations are distinct by definition, i.e., a global association cannot be assigned to another type. The

153 fraction of global, prevalent, and low-frequency associations was highest in the DCM layer and lowest 154 in the bathypelagic zone (third and fifth column in Table 1, Supplementary Figure 2B, 2D). Given that 155 the MS bathypelagic is warmer (median temperature of $13.78^{\circ} \mathrm{C}$ ) than the global ocean bathypelagic 156 (median temperature between $1.4^{\circ} \mathrm{C}$ in SPO and $4.41^{\circ} \mathrm{C}$ in NAO), we calculated these associations for 157 the global ocean only. We found slightly to moderately more global, prevalent, and low-frequency 158 associations in the global ocean when not considering the MS (fifth to seventh row in Table 1, 159 Supplementary Figure 2E-H).

Next, we determined regional associations within each depth layer. A regional association was defined as detected in at least one sample-specific subnetwork of one region and absent from all 162 subnetworks of the other five regions. Results indicated an increasing proportion of regional 163 associations with depth (Table 1, Figure 4A-B, Supplementary Figure 3). We found substantially more 
associations in the DCM and mesopelagic layers of the MS than corresponding layers of the global

ocean. This may reflect the different characteristics of these layers in the MS vs. the global ocean or

the massive differences in spatial dimensions between the global ocean and the MS. More surface and bathypelagic regional associations corresponded to the MS and NAO than in other regions (Table 1).

Most regional associations had low prevalence, i.e., they were present in a few sample-specific subnetworks within the region (Figure 4C). We found 235 prokaryotic highly prevalent (>70\%) regional associations in contrast to 89 eukaryotic and 24 associations between domains (Supplementary Material 1).

Previous studies have found a substantial vertical connectivity in the ocean microbiota, with surface microorganisms having an impact in deep sea counterparts (Mestre et al., 2018; Ruiz-González et al., 2020). Thus, here, we analyzed the vertical connectivity of microbial associations. Few associations appeared throughout the water column within a region: 327 prokaryotic, 119 eukaryotic, and 13 associations between domains (Supplementary Material 2). In general, most associations appearing in the meso- and bathypelagic did not appear in upper layers except for the MS and NAO where most and about half, respectively, of the bathypelagic associations already appeared in the mesopelagic (Figure 5). Specifically, 81.77 - 90.90\% mesopelagic and 43.54-72.71\% bathypelagic associations appeared for the first time in the five ocean basins (Supplementary Table 2). In the MS, $71.24 \%$ mesopelagic and $22.44 \%$ bathypelagic associations appeared for the first time and $69.71 \%$ of bathypelagic associations already appeared in the mesopelagic (Supplementary Table 2). This points to specific microbial interactions occurring in the deep ocean that do not occur in upper layers. In 184 addition, while most surface associations also appeared in the DCM in the MS, most surface associations disappeared with depth in the five ocean basins (Figure 5) suggesting that most surface ocean associations are not transferred to the deep sea, despite microbial sinking (Mestre et al., 2018). In fact, we observed that most deep ocean ASVs already appeared in the upper layers (Supplementary 
taxa are also found in surface waters, and that their presence in the deep sea is related to sinking processes (Mestre et al., 2018).

\section{Comparing subnetworks}

193 Vertical and horizontal spatial variability is expected to affect network topology via biotic and abiotic

194 variables as well as through dispersal processes (e.g., dispersal limitation). Yet, we have a limited understanding on how much marine microbial networks change due to these processes, thus analyzing the topology of subnetworks from specific ocean regions and depths is a first step to address this question. We compared the subnetworks of the six regions and depth layers using eight global network metrics (see Methods). We found that global network metrics change along the water column

199 (Supplementary Figure 5). As a general trend, subnetworks from deeper zones were more clustered 200 (transitivity) with higher average path length, stronger associations (average positive association scores) and lower assortativity (based on degree) compared to those in surface waters. Most DCM and bathypelagic subnetworks had the highest connectivity (edge density). Contrarily, in the MS, the surface subnetworks had the highest connectivity (Supplementary Figure 5).

To avoid predefined groupings into regions and depth layers, we grouped similar subnetworks via a local network metric (see Methods) and identified 36 clusters of 5 to 28 subnetworks (Supplementary Table 3). We found $13(36.1 \%)$ clusters that were dominated by surface subnetworks: six clusters (100\% surface subnetworks) from three to five oceans but not MS and seven clusters with

$20855-86 \%$ surface networks from two to five of the six ocean regions. In turn, 11 clusters were dominated 209 by a deeper layer: two DCM (64-90\%), five mesopelagic (62-83\%) and four bathypelagic dominated 210 clusters (60-69\%). Nine of these 11 clusters combined different regions except for one mesopelagic

211 and one bathypelagic dominated cluster representing exclusively the MS (Supplementary Table 3).

212 Furthermore, we found 11 clusters containing exclusively or mainly MS subnetworks in contrast to 213 only one cluster dominated by an ocean basin (NAO). 
Next, we built a more comprehensive representation of network similarities between

215 subnetworks via a minimal spanning tree (MST, see Methods) to underline the pervasive connectivity

216 of associations across depth and environmental gradients. The depth layers, ocean regions, location of

217 clusters, and environmental factors were projected onto the MST (Figure 6). Most surface subnetworks

218 were centrally located, while subnetworks from other depths appeared in different MST areas. Most

219 MS subnetworks were located in a specific branch of the MST, while the five oceans were mixed,

220 indicating homogeneity within oceans but network-based differences between the oceans and the MS.

221 However, subnetworks in the MST tended to connect to subnetworks from the same depth layer, cluster

222 or similar environmental conditions. All in all, the above results suggest a strong influence of 223 environmental gradients in shaping network topology and plankton associations, as previously 224 observed in epipelagic communities at global scale (Chaffron et al., 2020).

\section{DISCUSSION}

227 In this work, we disentangled and analyzed global and regional microbial associations across the 228 oceans' vertical and horizontal dimensions. We found a low number of global associations indicating 229 a potentially small global core interactome within each depth layer across six oceanic regions. Core 230 microorganisms are often defined as those appearing in most or all samples from similar habitats

231 (Shade \& Handelsman, 2012). We previously identified a core microbiota in a coastal MS observatory 232 based on both association patterns (Krabberød et al., 2021) and temporal recurrence of associations 233 (Deutschmann et al., 2021). Both studies indicate more robust microbial connectivity, suggesting a 234 broader core, in colder than in warmer seasons. In contrast, within each region, we found less highly 235 prevalent associations in the bathypelagic zone of the global ocean (pointing to a smaller regional core) 236 than in the upper layers, except from the NPO, having less highly prevalent associations in the meso237 than in the bathypelagic. In agreement, we found more regional bathypelagic associations than in upper 238 layers. Thus, associations may reflect the heterogeneity and isolation of the deep ocean regions due to 
239 deep currents, water masses, or the topography of the seafloor that may prevent microbial dispersal.

240 Moreover, the higher complexity of the deep ocean ecosystem may provide a higher number of

241 ecological niches potentially resulting in more regional associations and agreeing with our

242 observations. A high diversification of niches may be associated to the different quality and types

243 (labile, recalcitrant, etc.) of organic matter reaching the deep ocean from the epipelagic zone (Arístegui

244 et al., 2009), which is significantly different across oceanic regions (Hansell \& Carlson, 1998). In an

245 exploration of generalists versus specialist prokaryotic metagenome-assembled genomes (MAGs) in

246 the arctic Ocean, most of the specialists were linked to mesopelagic samples indicating that their

247 distribution was uneven across depth layers (Royo-Llonch et al., 2020). This is in agreement with

248 putatively more niches in the deep ocean than in upper ocean layers leading to more specialist taxa and

249 subsequently more regional associations.

Vertical connectivity in the ocean microbiome is partially modulated by surface productivity

251 through sinking particles (Mestre et al., 2018; Boeuf et al., 2019; Ruiz-González et al., 2020). An

252 analysis of eight stations, distributed across the Atlantic, Pacific and Indian oceans (including 4 depths:

253 Surface, DCM, meso- and bathypelagic), indicated that bathypelagic communities comprise both 254 endemic taxa as well as surface-related taxa arriving via sinking particles (Mestre et al., 2018). Ruiz-

255 González et al. (Ruiz-González et al., 2020) identified for both components (i.e. surface-related and

256 deep-endemic) the dominating phylogenetic groups: while Thaumarchaeota, Deltaproteobacteria,

257 OM190 (Planctomycetes) and Planctomycetacia (Planctomycetes) dominated the endemic

258 bathypelagic communities, Actinobacteria, Alphaproteobacteria, Gammaproteobacteria and

259 Flavobacteriia (Bacteroidetes) dominated the surface-related taxa in the bathypelagic zone. We found

260 association partners for each dominating phylogenetic group within each investigated type of

261 association, i.e., highly prevalent, regional, global, prevalent, and low-frequency associations. While

262 ASVs belonging to these taxonomic groups were present throughout the water column, specific

263 associations were observed especially in the mesopelagic and bathypelagic zones, which suggests 
264 specific associations between deep-sea endemic taxa. This is in agreement with a recent study that

265 found a remarkable taxonomic novelty in the deep ocean after analyzing 58 microbial metagenomes

266 from global samples, unveiling $\sim 68 \%$ archaeal and $~ 58 \%$ bacterial novel species (Acinas et al., 2021).

Less is known about associations found along the entire or a substantial fraction of the water

268 column, suggesting consortia of associated microorganisms that sink together or that populate large

269 vertical ranges of the water column. Associations present across all layers were few but may represent

270 interacting taxa that populate the entire water column or that sink together. However, given that we

271 targeted mainly picoplankton, we would not expect a considerable influence of sinking particles in the

272 vertical distribution of associations in this study. Some associations observed in the deep ocean may

273 correspond to consortia of taxa degrading sinking particles, or taxa that might have detached from

274 sinking particles, i.e., dual life-style taxa as observed in (Sebastián, Sánchez, et al., 2021).

275 Alternatively, microorganisms may have reached bathypelagic waters via fast-sinking processes,

276 embedded in (larger) particles (Agusti et al., 2015). By following this observation, a previous study

277 found that the abundances of microorganisms in deeper layers mirrored the changes in abundance of

278 microorganisms in shallower layers, at a single sampling station, indicating that communities

279 populating different ocean depths are not isolated from each other but linked, possibly through sinking

280 particles or migrating organisms transporting nutrients through the water column (Cram et al., 2015).

281 However, microbial co-occurrence alone does not suffice to infer microbial interactions, because

282 different mechanisms, such as selection or dispersal, influence species as well as their interactions

283 (Poisot et al., 2012). Our results suggest that microorganisms can potentially change their interaction

284 partners along vertical (and horizontal) scales and, to a lesser extent, maintain interactions along the 285 water column.

A study of global-ocean picoplanktonic eukaryotes through the water column (from the Epi- to

the Bathypelagic zone) found the highest and lowest relative metabolic activity for most eukaryotes in

288 the meso- and bathypelagic zones, respectively (Giner et al., 2020). Thus, we could hypothesize more 
competition in the mesopelagic zone and more beneficial interactions in the bathypelagic zone. In our study, mesopelagic subnetworks displayed the lowest connectivity in most regions on average, and we

291 found the strongest associations among both meso- and bathypelagic subnetworks. Moreover, we

292 found the highest clustering (transitivity) in the meso- and bathypelagic zones (relatively colder 293 waters) compared to the epipelagic zone (warmer waters). Similarly, a previous global-scale study

294 (Chaffron et al., 2020) concentrating on the epipelagic zone and including polar waters, found higher 295 edge density, association strength and clustering in polar (colder waters) compared to warmer waters. These results suggest that either microorganisms interact more in colder and darker environments or that their recurrence is higher due to a higher environmental selection exerted by low temperatures and no light. Alternatively, limited resources (primarily nutrients) in the surface versus deep ocean may prevent the establishment of specific microbial interactions. Furthermore, another explanation could be the higher diversity of ecological niches and, thus, a higher diversity of associations in the mesoand bathypelagic.

Through quantifying regional associations, our results indicated distinct associations in the MS, where most regional associations were observed compared to the global ocean, as previously shown in an epipelagic network (Lima-Mendez et al., 2015). Furthermore, we found a substantial number of regional associations in the NAO compared to other ocean basins, contrasting with the NAO having the lowest number of regional associations in a previous epipelagic network (Lima-Mendez et al., 2015). associations of the global ocean microbiome, from top to bottom layers, suggesting both global and regional interactions. Our analysis demonstrated the change of network topology across vertical (water

311 column) and horizontal (different regions) dimensions of the ocean. Furthermore, our results indicate 312 that associations have specific spatial distributions that are not just mirroring ASV distributions. 


\section{METHODS}

315 Dataset

316 Samples originated from two expeditions, Malaspina-2010 (Duarte, 2015) and Hotmix (Martínez-

317 Pérez et al., 2017). The former was onboard the R/V Hespérides and most ocean basins were sampled

318 between December 2010 and July 2011. Malaspina samples included i) MalaSurf, surface samples

319 (Ruiz-González et al., 2019; Logares et al., 2020), ii) MalaVP, vertical profiles (Giner et al., 2020), 320 and iii) MalaDeep, deep-sea samples, (Pernice et al., 2016; Salazar et al., 2016; Sanz-Sáez, 2021). For

321 the Hotmix expedition, sampling took place onboard the R/V Sarmiento de Gamboa between 27th 322 April and 29th May 2014 and represented a quasi-synoptic transect across the MS and the adjacent 323 North-East of the NAO. See details in Table 2.

DNA extractions are indicated in the papers associated with each dataset (Table 2). From the

DNA extractions, the 16S and 18S rRNA genes were amplified and sequenced. PCR amplification and sequencing of MalaSurf, MalaVP (18S), and Hotmix (16S) are indicated in the papers associated with

each dataset in Table 2. MalaVP (16S) and Hotmix (18S) were PCR-amplified and sequenced

328 following the same approach as in (Logares et al., 2020). MalaDeep samples were obtained from

329 (Pernice et al., 2016; Salazar et al., 2016) but re-sequenced in Genoscope (France) with different 330 primers, as described below. MalaSurf, MalaVP and Hotmix datasets were sequenced at RTL 331 Genomics (Texas, USA).

We used the same amplification primers for all samples. For the 16S, we amplified the V4-V5

333 hypervariable region using the primers 515F-Y and 926R (Parada et al., 2016). For the 18S, we 334 amplified the V4 hypervariable region with the primers TAReukFWD1 and TAReukREV3 (Stoeck et 335 al., 2010). See more details in (Logares et al., 2020). Amplicons were sequenced in Illumina MiSeq 336 or HiSeq2500 platforms (2x250 or 2x300 bp reads). Operational Taxonomic Units were delineated as 337 Amplicon Sequence Variants (ASVs) using DADA2 (Callahan et al., 2016), running each dataset 338 separately before merging the results. ASVs were assigned taxonomy using SILVA (Quast et al., 
339 2012), v132, for prokaryotes, and PR2 (Guillou et al., 2012), v4.11.1, for eukaryotes. ASVs

340 corresponding to Plastids, Mitochondria, Metazoa, and Plantae, were removed. Only samples with at

341 least 2000 reads were kept. The dataset contained several MalaDeep replicates, which we merged, and

342 two filter sizes: given the cell sizes of prokaryotes versus microeukaryotes, we selected the smallest

343 available filter size $(0.2-0.8 \mu \mathrm{m})$ for prokaryotes and the larger one $(0.8-20 \mu \mathrm{m})$ for microeukaryotes.

344 The other three datasets used filter sizes of 0.2-3 $\mu \mathrm{m}$. Additionally, we required that samples had

345 eukaryotic and prokaryotic data, resulting in 397 samples for downstream analysis: 122 MalaSurf, 83

346 MalaVP, 13 MalaDeep, and 179 Hotmix. We separated the samples into epipelagic, mesopelagic and

347 bathypelagic zone (Figure 1). Furthermore, we separated most epipelagic samples into surface and 348 deep-chlorophyll maximum (DCM) samples, but $18 \mathrm{MS}$ and 4 NAO samples belonged to neither. We

349 also considered environmental variables: Temperature $(2$ missing values $=\mathrm{mv})$, salinity $(2 \mathrm{mv})$,

350 fluorescence (3 mv), and inorganic nutrients $\mathrm{NO}_{3}{ }^{-}(36 \mathrm{mv}), \mathrm{PO}_{4}{ }^{3-}(38 \mathrm{mv})$, and $\mathrm{SiO}_{2}(37 \mathrm{mv})$, which

351 were measured as indicated elsewhere (Giner et al., 2020; Logares et al., 2020; Sebastián, Ortega-

352 Retuerta, et al., 2021). In specific samples, missing data on nutrient concentrations were estimated

353 from the World Ocean Database (Boyer et al., 2013).

355 Single static network

356 We constructed the single static network in four steps. First, we prepared the data for network 357 construction. We excluded rare microorganisms by keeping ASVs with a sequence abundance sum 358 above 100 reads and appearing in at least 20 samples (>5\%). The latter condition removes bigger 359 eukaryotes only appearing in the 13 MalaDeep eukaryotic samples of a bigger size fraction. To control 360 for data compositionality (Gloor et al., 2017), we applied a centered-log-ratio transformation 361 separately to the prokaryotic and eukaryotic tables before merging them.

Second, we inferred a (preliminary) network using FlashWeave (Tackmann et al., 2019), 363 selecting the options "heterogeneous" and "sensitive". FlashWeave was chosen as it can handle sparse 
364 datasets like ours, taking zeros into account and avoiding spurious correlations between ASVs that 365 share many zeros.

Third, we aimed to remove environmentally-driven edges. FlashWeave could detect indirect

367 edges and allows to supply additional metadata such as environmental variables, but currently does 368 not support missing data. Thus, we applied EnDED (Deutschmann et al. 2020), combining the methods

369 Interaction Information (with 0.05 significance threshold and 10000 iterations) and Data Processing

370 Inequality as done previously via artificially-inserted edges to connect all microbial nodes to the six

371 environmental parameters (Deutschmann et al., 2021). Although EnDED can handle missing

372 environmental data when calculating intermediate values relating ASV and environmental factors, it

373 would compute intermediate values for microbial edges using all samples. Thus, to avoid a possible

374 bias and speed up the calculation process, we applied EnDED individually for each environmental

375 factor, using only the samples containing values for the specific environmental factor.

Fourth, we removed isolated nodes, i.e., nodes without any edge. The resulting network

represented the single static network in our study.

Sample-specific subnetwork

380 We constructed 397 sample-specific subnetworks. Each subnetwork represented one sample and was 381 derived from the single static network, i.e., a subnetwork contained nodes and edges present in the 382 single static network but not vice versa. Consider sample $S_{R L}$ with $R$ being the marine region, and $L$ 383 the sample's depth layer. Let $e$ be an association between microorganisms $A$ and $B$. Then, association $384 e$ is present in the sample-specific subnetwork $N_{s}$, if

385 i. $\quad e$ is an association in the single static network,

386 ii. the microorganisms $A$ and $B$ are present within sample $s$, i.e., the abundances are above zero within that particular sample, and

iii. the association has a region and depth specific Jaccard index, $J_{R L}$, above $20 \%$ (see below). 
389 In addition to these three conditions, a node is present in a sample-specific subnetwork when connected

390 to at least one edge, i.e., we removed isolated nodes.

391 Regarding the third condition, we determined $J_{R L}$ for each association pair by computing within

392 each region and depth layer, the fraction of samples two microorganisms appeared together

393 (intersection) from the total samples at least one microorganism appears (union). Supplementary Table

3944 shows the number of edges using different thresholds. Given the heterogeneity of the dataset within

395 regions and depth layers, we decided to use a low threshold, keeping edges with a Jaccard index above

$39620 \%$ and removed edges below or equal to $20 \%$. We tested robustness by randomly drawing a subset

397 of samples from each region and depth combination. The subset contained between $10 \%$ and $90 \%$ of

398 the original samples. We rounded up decimal numbers to avoid zero sample subsets, e.g., $10 \%$ of 7

399 samples results in a subset of 1 sample. We excluded the DCM of the SPO because it contained only

400 one sample. Next, we recomputed the Jaccard index for the random subset. Lastly, requiring J>20\%,

401 we evaluated robustness determining i) how many edges were kept in the random subsamples

402 compared to all samples, and ii) how many edges were kept in the random subset that were also kept

403 when all samples were used. We repeated the procedure for each region-depth combination 1000 times.

\section{Spatial recurrence}

406 To determine an association's spatial recurrence, we calculated its prevalence as the fraction of 407 subnetworks in which the association was present. We determined association prevalence across the 408397 samples and each region-layer combination. We mapped the scores onto the single static network, 409 visualized in Gephi (Bastian et al., 2009), v.0.9.2, using the Fruchterman Reingold Layout 410 (Fruchterman \& Reingold, 1991) with a low gravity score of 0.5. We used the region-layer prevalence

411 to determine global and regional associations. We considered an association to be global within a 412 specific depth layer if its prevalence was above $70 \%$ in all regions. In turn, a regional association had 413 an association prevalence above $0 \%$ within a particular region-layer (present, appearing in at least one 
414 subnetwork) and 0\% within other regions of the same layer (absent, appearing in no subnetwork). In

415 addition, associations that are not global but appear in all regions over $50 \%$ are considered prevalent.

416 Similarly, associations that are not global nor prevalent but appear in all regions over $20 \%$ are

417 considered low-frequency. Thus, an association can be classified as i) global, ii) regional, iii) prevalent,

418 iv) low-frequency, and v) "other", i.e., associations that have not been classified into the previous

419 categories.

\section{Global network metrics}

422 We considered the number of nodes and edges and six other global network metrics of which most 423 were computed with functions of the igraph R-package (Csardi \& Nepusz, 2006). Edge density 424 indicating connectivity is computed through the number of actual edges divided by the number of 425 possible edges. The average path length is the average length of all shortest paths between nodes in a 426 network. Transitivity indicating how well a network is clustered is the probability that the nodes' 427 neighbors are connected. Assortativity measures if similar nodes tend to be connected, i.e., assortativity 428 (degree) is positive if high degree nodes tend to connect to other high degree nodes and negative 429 otherwise. Similarly, assortativity (Euk-Prok) is positive if eukaryotes tend to connect to other 430 eukaryotes and prokaryotes tend to connect to other prokaryotes. Lastly, we computed the average 431 positive association strength as the mean of all positive association scores provided by FlashWeave.

\section{Local network metric}

434 The previous global metrics disregard local structures' complexity, and topological analyses should 435 include local metrics (Espejo et al., 2020), e.g., graphlets (Pržulj et al., 2004). Here, we determined 436 network-dissimilarity between each pair of sample-specific subnetworks as proposed in (Yaveroğlu et 437 al., 2014), comparing network topology without considering specific ASVs. The network-dissimilarity 
438 is a distance measurement that is always positive: 0 if networks are identical and greater numbers 439 indicate greater dissimilarity.

440 Next, we constructed a Network Similarity Network (NSN), where each node is a subnetwork

441 and each node connects with all other nodes, i.e., the NSN was a complete graph. We assigned the 442 network-dissimilarity score as edge weight within the NSN. To simplify the NSN while preserving its 443 main patterns, we determined the minimal spanning tree (MST) of the NSN. The MST had 397 nodes 444 and 396 edges. The MST is a backbone, with no circular path, in which the edges are chosen so that 445 the edge weights sum is minimal and all nodes are connected, i.e., a path exists between any two nodes. 446 We determined the MST using the function mst in the igraph package in R (Prim, 1957; Csardi \& 447 Nepusz, 2006).

Using the network-dissimilarity (distance) matrix, we determined clusters of similar 449 subnetworks in python. First, we reduced the matrix to ten dimension using umap (McInnes et al., 450 2018) with the following parameter settings: $n \_$neighbors $=3$, min_dist $=0$, $n \_$components $=10$, 451 random_state=123, and metric='precomputed'. Second, we clustered the subnetworks (represented via 452 ten dimensions) with hdbscan (McInnes et al., 2017) setting the parameters to min_samples=3 and 453 min_clusters $=5$.

\section{Reproducibility}

R-Markdowns for data analysis including commands to run FlashWeave and EnDED 457 (environmentally-driven-edge-detection and computing Jaccard index) are publicly available: 458 https://github.com/InaMariaDeutschmann/GlobalNetworkMalaspinaHotmix. While the networks are 459 already available, the microbial sequence abundances (ASV table), taxonomic classifications, 460 environmental data including nutrients will be publicly available after acceptance. The data are of 461 course available upon request to reviewers. 


\section{Acknowledgements}

464 We thank all members of the Malaspina and Hotmix expeditions with the multiple projects funding 465 these collaborative efforts. Sampling was carried out thanks to the Consolider-Ingenio programme 466 (project Malaspina 2010 Expedition, ref. CSD2008-00077) and HOTMIX project (CTM2011467 30010/MAR), funded by the Spanish Ministry of Economy and Competitiveness Science and 468 Innovation. Part of the analyses have been performed at the Marbits bioinformatics core at ICM-CSIC 469 (https://marbits.icm.csic.es). This project and IMD received funding from the European Union's 470 Horizon 2020 research and innovation program under the Marie Skłodowska-Curie grant agreement no. 675752 (ESR2, http://www.singek.eu) to RL. RL was supported by a Ramón y Cajal fellowship 472 (RYC-2013-12554, MINECO, Spain). This work was also supported by the projects 473 INTERACTOMICS (CTM2015-69936-P, MINECO, Spain), MicroEcoSystems (240904, RCN, 474 Norway) and MINIME (PID2019-105775RB-I00, AEI, Spain) to RL. SC was supported by the CNRS 475 MITI through the interdisciplinary program Modélisation du Vivant (GOBITMAP grant). SC, DE and 476 SGA were funded by the H2020 project AtlantECO (award number 862923).

\section{Author's contributions}

479 The overall project was conceived and designed by RL. JMG, CMD, SGA, RM, JA were responsible 480 for the sampling and acquisition of contextual data. CRG, JP and MS processed specific samples in 481 the laboratory. RL processed the amplicon data generating the two ASV tables. They were the starting 482 point of the present study, which is part of the overall project. IMD developed the conceptual approach 483 and DE, SC, and RL contributed to its finalization. IMD performed the data analysis. ED, MS, CMD, 484 SGA, RM, JMG, DE, SC, and RL contributed with interpretation of the results. IMD wrote the original draft. All authors contributed to manuscript revisions and approved the final version of the manuscript.

487 Competing interests: The authors declare that they have no competing interests. 


\section{REFERENCES}

Acinas, S.G., Sánchez, P., Salazar, G., Cornejo-Castillo, F.M., Sebastián, M., Logares, R., Royo-llonch, M., Paoli, L., Sunagawa, S., Hingamp, P., Ogata, H., Lima-Mendez, G., Roux, S., González, J.M., Arrieta, J.M., Alam, I.S., Kamau, A., Bowler, C., Raes, J., Pesant, S., Bork, P., Agustí, S., Gojobori, T., Vaqué, D., Sullivan, M.B., Pedrós-Alió, C., Massana, R., Duarte, C.M., \& Gasol, J.M. (2021) Deep ocean metagenomes provide insight into the metabolic architecture of bathypelagic microbial communities. Communications Biology, 4, 604.

Agusti, S., González-Gordillo, J.I., Vaqué, D., Estrada, M., Cerezo, M.I., Salazar, G., Gasol, J.M., \& DUARTE, C.M. (2015) Ubiquitous healthy diatoms in the deep sea confirm deep carbon injection by the biological pump. Nature Communications, 6, 7608.

Arístegul, J., Gasol, J.M., DuARTe, C.M., \& HeRndld, G.J. (2009) Microbial oceanography of the dark ocean's pelagic realm. Limnology and Oceanography, 54, 1501-1529.

BALDAUF, S.L. (2008) An overview of the phylogeny and diversity of eukaryotes. Journal of Systematics and Evolution, 46, 263.

Bastian, M., Heymann, S., \& Jacomy, M. (2009) Gephi: An Open Source Software for Exploring and Manipulating Networks. ICWSM, 3.

BJoRbAEMMO, M.F.M., EVENSTAD, A., RøSAEG, L.L., KRABberøD, A.K., \& LOGARES, R. (2019) The planktonic protist interactome: where do we stand after a century of research? The ISME Journal, DOI: 10.1038/s41396-019-0542-5.

Boeuf, D., Edwards, B.R., Eppley, J.M., Hu, S.K., Poff, K.E., Romano, A.E., Caron, D.A., Karl, D.M., \& DELONG, E.F. (2019) Biological composition and microbial dynamics of sinking particulate organic matter at abyssal depths in the oligotrophic open ocean. Proc Natl Acad Sci USA, 116, 11824.

Boyer, T.P., Antonov, J.I., Baranova, O.K., Garcia, H.E., Johnson, D.R., Mishonov, A.V., O'Brien, T.D., Seidov, D., 1948-, SMolyar, I. (Igor), ZWeng, M.M., PAVER, C.R., LocarninI, R.A., Reagan, J.R., Forgy, C. (Carla), Grodsky, A., \& LEVITUS, S. (2013) World ocean database 2013. NOAA atlas NESDIS ; 72, DOI: 10.7289/V5NZ85MT.

Callahan, B.J., McMurdie, P.J., Rosen, M.J., Han, A.W., Johnson, A.J.A., \& Holmes, S.P. (2016) DADA2: High-resolution sample inference from Illumina amplicon data. Nature Methods, 13, 581-583.

Chaffron, S., Delage, E., Budinich, M., Vintache, D., Henry, N., Nef, C., Ardyna, M., Zayed, A.A., Junger, P.C., Galand, P.E., Lovejoy, C., Murray, A., Sarmento, H., Acinas, S., Babin, M., Iudicone, D., Jaillon, O., Karsenti, E., Wincker, P., KarP-Boss, L., Sullivan, M.B., Bowler, C., de VarGas, C., \& EVEILLARD, D. (2020) Environmental vulnerability of the global ocean plankton community interactome. bioRxiv, 2020.11.09.375295.

Chow, C.-E.T., KIM, D.Y., SAChDeVA, R., CARON, D.A., \& Fuhrman, J.A. (2014) Top-down controls on bacterial community structure: microbial network analysis of bacteria, T4-like viruses and protists. The ISME Journal, 8, 816-829.

Chow, C.-E.T., Sachdeva, R., Cram, J.A., Steele, J.A., Needham, D.M., Patel, A., Parada, A.E., \& Fuhrman, J.A. (2013) Temporal variability and coherence of euphotic zone bacterial communities over a decade in the Southern California Bight. The ISME Journal, 7, 2259-2273.

Coutinho, F.H., Meirelles, P.M., Moreira, A.P.B., Paranhos, R.P., Dutilh, B.E., \& Thompson, F.L. (2015) Niche distribution and influence of environmental parameters in marine microbial communities: a systematic review. PeerJ, 3, e1008.

Cram, J.A., XiA, L.C., Needham, D.M., SACHDEVA, R., Sun, F., \& Fuhrman, J.A. (2015) Cross-depth analysis of marine bacterial networks suggests downward propagation of temporal changes. The ISME Journal, 9, 2573-2586. 
CSARDI, G. \& NePUSZ, T. (2006) The igraph software package for complex network research. InterJournal, Complex Systems, 1695.

DELONG, E.F. (2009) The microbial ocean from genomes to biomes. Nature.

Deutschmann, I., Krabberød, A.K., Benites, L.F., latorre, F., Delage, E., Marrasé, C., Balagué, V., Gasol, J.M., Massana, R., Eveillard, D., Chaffron, S., \& Logares, R. (2021) Disentangling temporal associations in marine microbial networks. Research Square, DOI: 10.21203/rs.3.rs404332/v1.

DUARTE, C.M. (2015) Seafaring in the 21St Century: The Malaspina 2010 Circumnavigation Expedition. Limnology and Oceanography Bulletin, 24, 11-14.

Espejo, R., Mestre, G., Postigo, F., lumbreras, S., Ramos, A., Huang, T., \& Bompard, E. (2020) Exploiting graphlet decomposition to explain the structure of complex networks: the GHuST framework. Scientific Reports, 10, 12884.

Falkowski, P.G., Fenchel, T., \& Delong, E.F. (2008) The Microbial Engines That Drive Earth's Biogeochemical Cycles. Science.

FRUCHTERMAN, T.M.J. \& REINGOLD, E.M. (1991) Graph drawing by force-directed placement. Software: Practice and Experience, 21, 1129-1164.

Giner, C.R., Pernice, M.C., Balagué, V., Duarte, C.M., Gasol, J.M., logares, R., \& Massana, R. (2020) Marked changes in diversity and relative activity of picoeukaryotes with depth in the world ocean. The ISME Journal, 14, 437-449.

Gloor, G.B., Macklaim, J.M., PaWlowsky-Glahn, V., \& Egozcue, J.J. (2017) Microbiome Datasets Are Compositional: And This Is Not Optional. Frontiers in Microbiology, 8, 2224.

Guillou, L., Bachar, D., Audic, S., Bass, D., Berney, C., Bittner, L., Boutte, C., Burgaud, G., de Vargas, C., Decelle, J., del Campo, J., Dolan, J.R., Dunthorn, M., Edvardsen, B., Holzmann, M., Kooistra, W.H.C.F., Lara, E., Le Bescot, N., logares, R., Mahé, F., Massana, R., Montresor, M., Morard, R., Not, F., PaWlowski, J., Probert, I., Sauvadet, A.-L., Siano, R., Stoeck, T., Vaulot, D., Zimmermann, P., \& CHRISTEN, R. (2012) The Protist Ribosomal Reference database (PR\$^2\$): a catalog of unicellular eukaryote Small Sub-Unit rRNA sequences with curated taxonomy. Nucleic Acids Research, 41, D597-D604.

HANSELL, D.A. \& CARLSON, C.A. (1998) Deep-ocean gradients in the concentration of dissolved organic carbon. Nature, 395, 263-266.

Ibarbalz, F.M., Henry, N., Brandão, M.C., Martini, S., Busseni, G., Byrne, H., Coelho, l.P., Endo, H., Gasol, J.M., Gregory, A.C., Mahé, F., Rigonato, J., Royo-Llonch, M., Salazar, G., Sanz-Sáez, I., Scalco, E., Soviadan, D., Zayed, A.A., Zingone, A., Labadie, K., Ferland, J., Marec, C., Kandels, S., Picheral, M., Dimier, C., Poulain, J., Pisarev, S., Carmichael, M., Pesant, S., Acinas, S.G., Babin, M., Bork, P., Boss, E., Bowler, C., Cochrane, G., Vargas, C. de, Follows, M., Gorsky, G., Grimsley, N., Guidi, L., Hingamp, P., Iudicone, D., Jaillon, O., Kandels, S., KarP-Boss, L., Karsenti, E., Not, F., Ogata, H., Pesant, S., Poulton, N., Raes, J., Sardet, C., Speich, S., Stemmann, L., Sullivan, M.B., Sunagawa, S., Wincker, P., Babin, M., Boss, E., IUdicone, D., JaIllon, O., Acinas, S.G., Ogata, H., Pelletier, E., Stemmann, L., Sullivan, M.B., Sunagawa, S., Bopp, L., Vargas, C. de, Karp-Boss, L., Wincker, P., Lombard, F., BOWLeR, C., \& Zinger, L. (2019) Global Trends in Marine Plankton Diversity across Kingdoms of Life. Cell, 179, 1084-1097.e21.

KRABberøD, A.K., BJoRBAEKMO, M.F.M., SHALCHIAN-TABRIZI, K., \& LOGARES, R. (2017) Exploring the oceanic microeukaryotic interactome with metaomics approaches. Aquatic Microbial Ecology, 79, 112.

Krabberød, A.K., Deutschmann, I.M., Bjorbekmo, M.F.M., Balagué, V., Giner, C.R., Ferrera, I., Garcés, E., MASSANA, R., GASOL, J.M., \& LOGARES, R. (2021) Long-term patterns of an interconnected core marine microbiota. bioRxiv, 2021.03.18.435965. 
LAYEghifard, M., HWANG, D.M., \& GuttMan, D.S. (2017) Disentangling Interactions in the Microbiome: A Network Perspective. Trends in Microbiology.

LeWIS, W.H., TAHON, G., Geesink, P., SousA, D.Z., \& EtTEMA, T.J.G. (2020) Innovations to culturing the uncultured microbial majority. Nature Reviews Microbiology, DOI: 10.1038/s41579-02000458-8.

lima-Mendez, G., Faust, K., Henry, N., Decelle, J., Colin, S., Carcillo, F., Chaffron, S., Ignacio-Espinosa, J.C., RouX, S., Vincent, F., Bittner, L., DarzI, Y., Wang, J., Audic, S., Berline, L., Bontempi, G., Cabello, A.M., Coppola, L., Cornejo-Castillo, F.M., d'OVidio, F., De Meester, L., Ferrera, I., GaretDelmas, M.-J., Guidi, L., Lara, E., Pesant, S., Royo-Llonch, M., Salazar, G., Sánchez, P., Sebastian, M., Souffreau, C., Dimier, C., Picheral, M., Searson, S., Kandels-Lewis, S., Gorsky, G., Not, F., Ogata, H., Speich, S., Stemmann, L., Weissenbach, J., Wincker, P., ACINAS, S.G., Sunagawa, S., Bork, P., Sullivan, M.B., Karsenti, E., Bowler, C., De Vargas, C., \& RaES, J. (2015) Determinants of community structure in the global plankton interactome. Science, 348, 1262073.

Logares, R., Deutschmann, I.M., Junger, P.C., Giner, C.R., Krabber $\varnothing$ D, A.K., Schmidt, T.S.B., RubinatRipoll, L., Mestre, M., Salazar, G., Ruiz-González, C., Sebastián, M., de Vargas, C., Acinas, S.G., DuARTE, C.M., GASOL, J.M., \& MASSANA, R. (2020) Disentangling the mechanisms shaping the surface ocean microbiota. Microbiome, 8, 55.

Mandakovic, D., Rojas, C., Maldonado, J., latorre, M., Travisany, D., Delage, E., Bihouée, A., Jean, G., díaz, F.P., Fernández-Gómez, B., Cabrera, P., Gaete, A., Latorre, C., Gutiérrez, R.A., MaAss, A., Cambiazo, V., NavarRete, S.A., Eveillard, D., \& GonzÁlez, M. (2018) Structure and co-occurrence patterns in microbial communities under acute environmental stress reveal ecological factors fostering resilience. Scientific Reports, 8, 5875.

Martínez-Pérez, A.M., Osterholz, H., Nieto-Cid, M., Álvarez, M., Dittmar, T., \& Álvarez-Salgado, X.A. (2017) Molecular composition of dissolved organic matter in the Mediterranean Sea. Limnology and Oceanography, 62, 2699-2712.

MASSANA, R. \& LOGARES, R. (2013) Eukaryotic versus prokaryotic marine picoplankton ecology. Environmental Microbiology, 15, 1254-1261.

McInNes, L., Healy, J., \& Astels, S. (2017) hdbscan: Hierarchical density based clustering. The Journal of Open Source Software, 2, 205.

McInNes, L., HeAly, J., SAUL, N., \& Grossberger, L. (2018) UMAP: Uniform Manifold Approximation and Projection. The Journal of Open Source Software, 3, 861.

Mestre, M., Ruiz-González, C., Logares, R., Duarte, C.M., Gasol, J.M., \& Sala, M.M. (2018) Sinking particles promote vertical connectivity in the ocean microbiome. Proc Natl Acad Sci USA, 115, E6799.

Milici, M., Deng, Z.-L., Tomasch, J., Decelle, J., Wos-Oxley, M.L., Wang, H., JáURegui, R., Plumeier, I., Giebel, H.-A., BadeWien, T.H., Wurst, M., Pieper, D.H., Simon, M., \& Wagner-Döbler, I. (2016) Co-occurrence Analysis of Microbial Taxa in the Atlantic Ocean Reveals High Connectivity in the Free-Living Bacterioplankton. Frontiers in Microbiology, 7, 649.

NeEdham, D.M., SACHDEVA, R., \& Fuhrman, J.A. (2017) Ecological dynamics and co-occurrence among marine phytoplankton, bacteria and myoviruses shows microdiversity matters. The ISME Journal, 11, 1614-1629.

PARAdA, A.E. \& Fuhrman, J.A. (2017) Marine archaeal dynamics and interactions with the microbial community over 5 years from surface to seafloor. The ISME Journal, 11, 2510-2525.

ParadA, A.E., NeEdHAM, D.M., \& Fuhrman, J.A. (2016) Every base matters: assessing small subunit rRNA primers for marine microbiomes with mock communities, time series and global field samples. Environmental Microbiology, 18, 1403-1414. 
Peoples, L.M., Donaldson, S., Osuntokun, O., XiA, Q., Nelson, A., Blanton, J., Allen, E.e., Church, M.J., \& BARTLETT, D.H. (2018) Vertically distinct microbial communities in the Mariana and Kermadec trenches. PLOS ONE, 13, 1-21.

Pernice, M.C., Giner, C.R., Logares, R., Perera-Bel, J., Acinas, S.G., Duarte, C.M., Gasol, J.M., \& Massana, R. (2016) Large variability of bathypelagic microbial eukaryotic communities across the world's oceans. The ISME Journal, 10, 945-958.

Poisot, T., Canard, E., Mouillot, D., Mouquet, N., \& Gravel, D. (2012) The dissimilarity of species interaction networks. Ecology Letters, 15, 1353-1361.

PRIM, R.C. (1957) Shortest connection networks and some generalizations. The Bell System Technical Journal, 36, 1389-1401.

PRžUL, N., CORNEIL, D.G., \& JURISICA, I. (2004) Modeling interactome: scale-free or geometric? Bioinformatics, 20, 3508-3515.

Quast, C., Pruesse, E., Yilmaz, P., Gerken, J., Schweer, T., Yarza, P., Peplies, J., \& Glöckner, F.O. (2012) The SILVA ribosomal RNA gene database project: improved data processing and web-based tools. Nucleic Acids Research, 41, D590-D596.

Royo-llonch, M., Sánchez, P., Ruiz-González, C., Salazar, G., Pedrós-Alió, C., labadie, K., Paoli, L., Chaffron, S., Eveillard, D., Karsenti, E., Sunagawa, S., Wincker, P., Karp-Boss, L., Bowler, C., \& ACINAS, S.G. (2020) Ecogenomics of key prokaryotes in the arctic ocean. bioRxiv, 2020.06.19.156794.

Ruiz-González, C., Logares, R., Sebastián, M., Mestre, M., Rodríguez-Martínez, R., Galí, M., Sala, M.M., ACINAS, S.G., DUARTE, C.M., \& GASOL, J.M. (2019) Higher contribution of globally rare bacterial taxa reflects environmental transitions across the surface ocean. Molecular Ecology, 28, 1930-1945.

Ruiz-González, C., Mestre, M., Estrada, M., Sebastián, M., Salazar, G., Agustí, S., Moreno-Ostos, E., Reche, I., Álvarez-Salgado, X.A., Morán, X.A.G., Duarte, C.M., Sala, M.M., \& Gasol, J.M. (2020) Major imprint of surface plankton on deep ocean prokaryotic structure and activity. Molecular Ecology, 29, 1820-1838.

Salazar, G., Cornejo-Castillo, F.M., Benítez-Barrios, V., Fraile-Nuez, E., Álvarez-Salgado, X.A., Duarte, C.M., GASOL, J.M., \& ACINAS, S.G. (2016) Global diversity and biogeography of deep-sea pelagic prokaryotes. The ISME Journal, 10, 596-608.

Salazar, G., Paoli, L., Alberti, A., Huerta-Cepas, J., Ruscheweyh, H.-J., Cuenca, M., Field, C.M., Coelho, L.P., Cruaud, C., Engelen, S., Gregory, A.C., Labadie, K., Marec, C., Pelletier, E., Royo-Llonch, M., Roux, S., Sánchez, P., Uehara, H., Zayed, A.A., Zeller, G., Carmichael, M., Dimier, C., Ferland, J., Kandels, S., Picheral, M., Pisarev, S., Poulain, J., Acinas, S.G., Babin, M., Bork, P., Boss, E., Bowler, C., Cochrane, G., Vargas, C. de, Follows, M., Gorsky, G., Grimsley, N., Guidi, L., Hingamp, P., Iudicone, D., Jaillon, O., Kandels-Lewis, S., Karp-Boss, L., Karsenti, E., Not, F., Ogata, H., Pesant, S., Poulton, N., Raes, J., Sardet, C., Speich, S., Stemmann, L., Sullivan, M.B., Sunagawa, S., Wincker, P., ACINAS, S.G., BABIN, M., Bork, P., BOWler, C., VARGAS, C. de, GUIDI, L., Hingamp, P., iudicone, D., Karp-Boss, L., Karsenti, E., Ogata, H., Pesant, S., Speich, S., Sullivan, M.B., Wincker, P., \& SunAGAWA, S. (2019) Gene Expression Changes and Community Turnover Differentially Shape the Global Ocean Metatranscriptome. Cell, 179, 1068-1083.e21.

SANZ-SÁEZ, I. (2021) Contribution of marine heterotrophic cultured bacteria to microbial diversity and mercury detoxification.

Sebastián, M., Ortega-Retuerta, E., Gómez-Consarnau, L., Zamanillo, M., Álvarez, M., Arístegui, J., \& GASOL, J.M. (2021) Environmental and physical barriers drive the basin-wide spatial structuring of Mediterranean Sea and adjacent Eastern Atlantic Ocean prokaryotic communities. Submitted. 
Sebastián, M., Sánchez, P., Salazar, G., Álvarez-Salgado, X.A., Reche, I., Morán, X.A.G., Sala, M.M., DUARTE, C.M., ACINAS, S.G., \& GASOL, J.M. (2021) The quality of dissolved organic matter shapes the biogeography of the active bathypelagic microbiome. bioRxiv, 2021.05.14.444136.

SeYmour, J.R., AMin, S.A., RAINA, J.-B., \& StOCKER, R. (2017) Zooming in on the phycosphere: the ecological interface for phytoplankton-bacteria relationships. Nature Microbiology, 2, 17065.

ShAde, A. \& HANDELSMAN, J. (2012) Beyond the Venn diagram: the hunt for a core microbiome. Environmental Microbiology, 14, 4-12.

Steele, J.A., Countway, P.D., XiA, L., Vigil, P.D., Beman, J.M., KIM, D.Y., Chow, C.-E.T., SAChdeva, R., Jones, A.C., Schwalbach, M.S., Rose, J.M., Hewson, I., Patel, A., Sun, F., Caron, D.A., \& Fuhrman, J.A. (2011) Marine bacterial, archaeal and protistan association networks reveal ecological linkages. The ISME Journal, 5, 1414-1425.

Stoeck, T., Bass, D., Nebel, M., Christen, R., Jones, M.D.M., Breiner, H.-W., \& Richards, T.A. (2010) Multiple marker parallel tag environmental DNA sequencing reveals a highly complex eukaryotic community in marine anoxic water. Molecular Ecology, 19, 21-31.

Sunagawa, S., Coelho, L.P., Chaffron, S., Kultima, J.R., Labadie, K., Salazar, G., Djahanschiri, B., Zeller, G., Mende, D.R., Alberti, A., Cornejo-Castillo, F.M., Costea, P.I., Cruaud, C., D'Ovidio, F., Engelen, S., Ferrera, I., Gasol, J.M., Guidi, L., Hildebrand, F., Kokoszka, F., Lepoivre, C., Lima-Mendez, G., Poulain, J., Poulos, B.T., Royo-llonch, M., Sarmento, H., Vieira-Silva, S., Dimier, C., Picheral, M., Searson, S., Kandels-Lewis, S., Bowler, C., de Vargas, C., Gorsky, G., Grimsley, N., Hingamp, P., Iudicone, D., Jaillon, O., Not, F., Ogata, H., Pesant, S., Speich, S., Stemmann, L., Sullivan, M.B., WeissenbaCh, J., WinCKer, P., KARSENTI, E., RAES, J., ACINAS, S.G., \& Bork, P. (2015) Structure and function of the global ocean microbiome. Science, 348, 1261359.

TACKMANN, J., Rodrigues, J.F.M., \& VON MERING, C. (2019) Rapid Inference of Direct Interactions in Large-Scale Ecological Networks from Heterogeneous Microbial Sequencing Data. Cell Systems, 9, 286-296.e8.

VeLLEND, M. (2020) The theory of ecological communities (MPB-57). Princeton University Press.

XU, Z., WANG, M., WU, W., LI, Y., LIU, Q., HAN, Y., JIANG, Y., SHAO, H., McMINN, A., \& LIU, H. (2018) Vertical Distribution of Microbial Eukaryotes From Surface to the Hadal Zone of the Mariana Trench. Frontiers in Microbiology, 9, 2023.

YaVeroǦlu, Ö.N., Malod-Dognin, N., DaVIS, D., LeVnaJic, Z., JanJic, V., KaRAPANDZA, R., Stojmirovic, A., \& PRŽUL, N. (2014) Revealing the Hidden Language of Complex Networks. Scientific Reports, 4, 4547. 


\section{FIGURES}

Figure 1: Sampling scheme. Location, number, and depth range of samples from the epipelagic zone including surface and DCM layer, the mesopelagic zone, and the bathypelagic zone from the global tropical and subtropical ocean and the Mediterranean Sea.

713 Figure 2: Spatial recurrence. A) Association prevalence showing the fraction of subnetworks in which an association appeared considering all depth layers across the global tropical and subtropical ocean and the Mediterranean Sea. Associations that occurred more often (black) appeared in the middle of the single static network visualization. Most edges had a low prevalence (blue) $<20 \%$.

B) The samplespecific subnetworks of the four ocean layers (rows): surface (SRF), DCM, mesopelagic (MES), and bathypelagic (BAT), and the six regions (columns). The histograms show the association prevalence within each depth layer and region (excluding absent associations, i.e., $0 \%$ prevalence). The number of samples appears in the upper left corner, the number of edges with a prevalence $>0 \%$ in the upper right corner, and the depth range in the lower right corner (in $\mathrm{m}$ below surface). Note that the prevalence goes up to $100 \%$ in B) vs. $66.5 \%$ in A).

Figure 3: Highly prevalent associations for each region and depth layer. If an association appears in more than $70 \%$ of subnetworks it is classified as highly prevalent. The four ocean layers (rows) are surface (SRF), DCM, mesopelagic (MES), and bathypelagic (BAT). The number of samples appears in the upper left corner, the number of edges in the upper right corner, and the depth range in the lower right corner (in m below surface).

Figure 4: Classification of associations. An association can be classified into global (>70\% prevalence, not considering the MS), prevalent ( $>50 \%$, not considering the MS), low-frequency (>20\%, not considering the MS), regional, and other. Regional associations are assigned to one of six ocean basins. The number A) and fraction B) of each type of association are shown for each depth layer: surface (SRF) and DCM (epipelagic), mesopelagic (MES) and bathypelagic (BAT). Color indicates the type of classification. The associations have been classified into the five types based on their prevalence in each region. The prevalence of associations is shown in C). For instance, global associations have a prevalence above $70 \%$ in each region (not considering the MS). Regional associations are present in one region (indicated with yellow with mainly low prevalence $>0 \%$ ) and absent in all other regions ( $0 \%$ prevalence not shown in graph). 
741 Figure 5: Microbial associations across depth layers. For each region and taxonomic domain, we color 742 associations based on when they first appeared: surface (S, yellow), DCM (D, orange), mesopelagic 743 (M, red), and bathypelagic (B, black). Absent ASVs are grouped in the white box. Columns show 744 associations between archaea (Arc), bacteria (Bac), and eukaryotes (Euk).

746 Figure 6: Minimal Spanning Tree. Each subnetwork is a node in the MST and represents a sample.

747 Nodes are colored according to A) the sample's depth layer, B) the samples ocean region, C) the 748 subnetworks cluster, and D) selected environmental factors. In C), the barplots indicate the different 749 layers within each cluster colored as in A). 


\section{TABLES}

752

Table 1: Number of classified associations per depth layer. The sum of classified associations (including Other) is the number of present associations. Absent associations appear in other layers but in no subnetwork of a given layer. Global, prevalent, and low-frequency associations have been computed with and without considering the MS. The proportion of regional associations increased with depth (gray row).

\begin{tabular}{crrrr}
\hline Depth layer & Epipelagic (Surface) & Epipelagic (DCM) & Mesopelagic & Bathypelagic \\
\hline Global & $26(0.14 \%)$ & $23(0.31 \%)$ & $21(0.20 \%)$ & - \\
Prevalent & $22(0.12 \%)$ & $47(0.64 \%)$ & $10(0.10 \%)$ & $7(0.07 \%)$ \\
Low-frequency & $105(0.58 \%)$ & $160(2.17 \%)$ & $212(2.05 \%)$ & $51(0.51 \%)$ \\
\hline Global (no MS) & $86(0.47 \%)$ & $52(0.70 \%)$ & $28(0.27 \%)$ & $9(0.09 \%)$ \\
Prevalent (no MS) & $207(1.14 \%)$ & $76(1.03 \%)$ & $27(0.26 \%)$ & $28(0.28 \%)$ \\
Low-frequency (no MS) & $1361(7.46 \%)$ & $219(2.97 \%)$ & $342(3.30 \%)$ & $489(4.84 \%)$ \\
\hline Regional & $2014(11.05 \%)$ & $2290(31.03 \%)$ & $3420(33.00 \%)$ & $3669(36.33 \%)$ \\
MS & $596(3.27 \%)$ & $1295(17.55 \%)$ & $2254(21.75 \%)$ & $1217(12.05 \%)$ \\
NAO & $577(3.16 \%)$ & $306(4.15 \%)$ & $422(4.07 \%)$ & $1522(15.07 \%)$ \\
SAO & $162(0.89 \%)$ & $304(4.12 \%)$ & $301(2.90 \%)$ & $143(1.42 \%)$ \\
SPO & $152(0.83 \%)$ & $105(1.42 \%)$ & $40(0.39 \%)$ & $109(1.08 \%)$ \\
NPO & $298(1.63 \%)$ & $133(1.80 \%)$ & $204(1.97 \%)$ & $516(5.11 \%)$ \\
IO & $229(1.26 \%)$ & $147(1.99 \%)$ & $199(1.92 \%)$ & $162(1.60 \%)$ \\
\hline Other* & $16067(88.12 \%)$ & $4860(65.85 \%)$ & $6701(64.66 \%)$ & $6372(63.10 \%)$ \\
\hline Other (no MS) & $14566(79.88 \%)$ & $4743(64.27 \%)$ & $6547(62.17 \%)$ & $55904(58.46 \%)$ \\
\hline Present & $18234(100 \%)$ & $7380(100 \%)$ & $10364(100 \%)$ & $10099(100 \%)$ \\
Absent & 10884 & 21738 & 18754 & 19019 \\
\hline
\end{tabular}

${ }^{*}$ The number of unclassified (Other) associations is computed from present, regional, global, prevalent, and low-frequency associations. The last three 
bioRxiv preprint doi: https://doi.org/10.1101/2021.07.12.451729; this version posted July 12,2021 . The copyright holder for this preprint (which was not certified by peer review) is the author/funder, who has granted bioRxiv a license to display the preprint in perpetuity. It is made available under aCC-BY-NC-ND 4.0 International license.

760 Table 2: Dataset compilation. Our data was a compilation of different datasets. We required that each location had to provide data for

761 both eukaryotes and prokaryotes, which resulted in 397 samples. This condition allowed only 13 MalaDeep samples.

\begin{tabular}{|c|c|c|c|c|c|c|c|c|c|}
\hline Dataset & $\begin{array}{l}\text { Samples } \\
\text { used for } \\
\text { analysis }\end{array}$ & Stations & $\begin{array}{c}\text { Depth } \\
\text { range } \\
(\mathrm{m}) \\
\end{array}$ & $\begin{array}{c}\text { Water } \\
\text { sampl } \\
\text { es } \\
\end{array}$ & $\begin{array}{c}\text { Size } \\
\text { Fraction } \\
(\mu \mathrm{m})\end{array}$ & $16 \mathrm{~S}$ & $18 \mathrm{~S}$ & Reference & $\begin{array}{c}\text { ENA accession } \\
\text { number }\end{array}$ \\
\hline \multicolumn{10}{|l|}{ Malaspina } \\
\hline MalaSurf & 122 & 120 & 3 & 122 & $0.2-3$ & 122 & 124 & $\begin{array}{l}\text { (Ruiz- } \\
\text { González et } \\
\text { al., 2019; } \\
\text { Logares et } \\
\text { al., 2020) }\end{array}$ & $\begin{array}{l}\text { PRJEB23913 [18S } \\
\text { rRNA genes], } \\
\text { PRJEB25224 [16S } \\
\text { rRNA genes] }\end{array}$ \\
\hline MalaVP & 83 & 13 & $3-4000$ & 91 & $0.2-3$ & 91 & 83 & $\begin{array}{l}\text { (Giner et al., } \\
\text { 2020) \& This } \\
\text { study }\end{array}$ & $\begin{array}{l}\text { PRJEB23771 [18S } \\
\text { rRNA genes], } \\
\text { PRJEB45015 [16S } \\
\text { rRNA genes] }\end{array}$ \\
\hline $\begin{array}{l}\text { MalaDeep } \\
\quad \text { (Prok) }\end{array}$ & 13 & 30 & $\sim 4000$ & 60 & $0.2-0.8$ & 41 & - & $\begin{array}{l}\text { (Sanz-Sáez, } \\
\text { 2021) }\end{array}$ & PRJEB45011 \\
\hline $\begin{array}{l}\text { MalaDeep } \\
\text { (Euk) }\end{array}$ & 13 & 27 & $\begin{array}{l}2400- \\
4000\end{array}$ & 27 & $0.8-20$ & - & 82 & This study & PRJEB45014 \\
\hline Hotmix & 179 & 29 & $3-4539$ & 188 & $0.2-3$ & 188 & 179 & $\begin{array}{l}\text { Sebastián, } \\
\text { Ortega- } \\
\text { Retuerta, et } \\
\text { al., 2021) }\end{array}$ & $\begin{array}{c}\text { PRJEB44683 } \\
\text { [18S rRNA genes], } \\
\text { PRJEB44474 [16S } \\
\text { rRNA genes] }\end{array}$ \\
\hline
\end{tabular}




\section{SUPPLEMENTARY MATERIAL}

\section{SUPPLEMENTARY FIGURES}

766 Supplementary Figure 1: Robustness of the third condition for generating sample-specific 767 subnetworks for each region and depth with sufficient samples (DCM layer from the SPO was removed 768 because it contained only one sample). Within each region and depth, the set of samples was randomly subsampled containing between $10 \%$ to $90 \%$ of the original set using all samples. The $y$-axis shows the fraction of edges that were kept in the subsampled set compared to the original set. We considered A) only the number of kept edges and B) which edges were kept.

Supplementary Figure 2: Associations occurring in each region and depth layer. If an association appears in more than $20 \%$ of subnetworks in each region, it is classified as low-frequency, $>50 \%$ prevalent, and $>70 \%$ global. The number of samples appears in the upper left corner, the number of edges in the upper right corner, and the depth range in the lower right corner (in $\mathrm{m}$ below surface). We classified the associations considering all six regions (A-D) and considering the five ocean basins neglecting the MS (E-H).

Supplementary Figure 3: Regional associations occurring in each region and depth layer. Within a particular depth layer, if an association appears in at least one subnetwork (present) in one region and in no subnetwork (absent) in other regions, it is classified as regional. The four ocean layers (rows) are surface (SRF), DCM, mesopelagic (MES), and bathypelagic (BAT). The number of samples appears in the upper left corner, the number of edges in the upper right corner, and the depth range in the lower right corner (in m below surface).

Supplementary Figure 4: ASVs across depth layers. For each region, we color ASVs based on the layer they first appeared: surface (S, yellow), DCM (D, orange), mesopelagic (M, red), and bathypelagic (B, black). Absent ASVs are grouped in box "a". An ASV only appearing in the bathypelagic, is assigned to box "a" in above layers. That is, an ASV detected in the surface and present in the DCM but absent in lower layers, appears in the box (S) in the surface and DCM layer, but in box " $\mathrm{a}$ " in the meso- and bathypelagic layer. An ASV cannot be assigned to two layers. Note that most ASVs in the bathypelagic zone have been already detected in upper layers because most ASVs are assigned to the boxes "S", "D", and "M" instead of "B".

Supplementary Figure 5: Global network metrics grouped by region and depth layer. 
bioRxiv preprint doi: https://doi.org/10.1101/2021.07.12.451729; this version posted July 12,2021 . The copyright holder for this preprint (which was not certified by peer review) is the author/funder, who has granted bioRxiv a license to display the preprint in perpetuity. It is made available under aCC-BY-NC-ND 4.0 International license.

798

799

800

801

802

803

804

805

806

807

\section{SUPPLEMENTARY TABLES}

Supplementary Table 1: Number of environmentally-driven edges detected by EnDED. We removed environmentally-driven edges (indirect) from the preliminary network, which contained 31966 edges. Only edges that were not environmentally-driven by any environmental factor (not indirect) remained in the network.

\begin{tabular}{lrrr}
\hline Environmental factor & Number of samples & indirect & Not indirect \\
\hline Fluorescence & 394 & $4(0.01 \%)$ & 31962 \\
NO3 & 361 & $1563(4.9 \%)$ & 30403 \\
PO4 & 359 & $1357(4.2 \%)$ & 30609 \\
Salinity & 395 & $67(0.2 \%)$ & 31899 \\
SiO4 & 360 & $632(2.0 \%)$ & 31334 \\
Temperature & 395 & $622(1.9 \%)$ & 31344 \\
\hline All & & $2848(8.9 \%)$ & $29118(91.1 \%)$ \\
& & 1779 removed by 1 & \\
& & +751 removed by 2 & \\
& & +308 removed by 3 & \\
\hline
\end{tabular}

Supplementary Table 2: Fraction of microbial associations across depth layers. For each region and layer (rows), we determined the constitution of associations (in percentage \%) classifying them based on their first appearance (columns): surface, DCM, mesopelagic, and bathypelagic. We indicated the fractions above $40 \%$ in grey.

\begin{tabular}{|c|c|c|c|c|c|}
\hline Region & Layer & Surface & $\mathrm{DCM}$ & Mesopelagic & Bathypelagic \\
\hline \multirow[t]{4}{*}{ MS } & SRF & 100.00 & & & \\
\hline & DCM & 45.14 & 54.86 & & \\
\hline & Mesopelagic & 10.35 & 18.42 & 71.24 & \\
\hline & Bathypelagic & 2.73 & 5.12 & 69.71 & 22.44 \\
\hline \multirow[t]{4}{*}{ NAO } & SRF & 100.00 & & & \\
\hline & DCM & 68.30 & 31.70 & & \\
\hline & Mesopelagic & 11.64 & 6.59 & 81.77 & \\
\hline & Bathypelagic & 11.62 & 1.35 & 43.49 & 43.54 \\
\hline \multirow[t]{4}{*}{ SAO } & SRF & 100.00 & & & \\
\hline & DCM & 45.08 & 54.92 & & \\
\hline & Mesopelagic & 6.15 & 8.50 & 85.35 & \\
\hline & Bathypelagic & 12.22 & 6.30 & 26.97 & 54.61 \\
\hline \multirow[t]{4}{*}{ SPO } & SRF & 100.00 & & & \\
\hline & DCM & 50.07 & 49.93 & & \\
\hline & Mesopelagic & 6.44 & 2.66 & 90.90 & \\
\hline & Bathypelagic & 9.81 & 3.32 & 14.15 & 72.71 \\
\hline \multirow[t]{4}{*}{ NPO } & SRF & 100.00 & & & \\
\hline & DCM & 54.23 & 45.77 & & \\
\hline & Mesopelagic & 8.33 & 6.06 & 85.61 & \\
\hline & Bathypelagic & 17.46 & 5.34 & 19.92 & 57.28 \\
\hline \multirow[t]{4}{*}{10} & SRF & 100.00 & & & \\
\hline & DCM & 39.23 & 60.77 & & \\
\hline & Mesopelagic & 5.92 & 7.87 & 86.21 & \\
\hline & Bathypelagic & 11.00 & 3.84 & 29.61 & 55.56 \\
\hline
\end{tabular}


809 Supplementary Table 3 Subnetwork cluster. Clusters dominated, i.e. over 50\%, by one layer or one region are indicated in grey. The last row shows unassigned subnetworks.

\begin{tabular}{|c|c|c|c|c|c|c|c|c|c|c|c|c|}
\hline \multirow{2}{*}{$\begin{array}{l}\text { cluster } \\
\text { ID }\end{array}$} & \multirow{2}{*}{$\begin{array}{c}\text { Dominated } \\
\text { by }\end{array}$} & \multirow[b]{2}{*}{ Size } & \multicolumn{5}{|c|}{ Fraction of depth layers } & \multicolumn{5}{|c|}{ Number of regions (if no number if indicated, it is $1 \mathrm{x}$ ) } \\
\hline & & & $\operatorname{SRF}^{\mathrm{E}}$ & $\begin{array}{l}\text { pipelagic } \\
\text { EPI }\end{array}$ & DCM & $\begin{array}{l}\text { Meso- } \\
\text { pelagic }\end{array}$ & $\begin{array}{l}\text { Bathy- } \\
\text { pelagic }\end{array}$ & pelagic & $\begin{array}{l}\text { Epipelagic } \\
\text { EPI }\end{array}$ & DCM & $\begin{array}{l}\text { Meso- } \\
\text { MES }\end{array}$ & $\begin{array}{l}\text { Bathy- } \\
\text { BAT }\end{array}$ \\
\hline 1 & MS & 5 & 20.00 & 20.00 & 20.00 & 20.00 & 20.00 & SAO & MS & NAO & MS & MS \\
\hline 2 & MS & 10 & 10.00 & - & 20.00 & 20.00 & 50.00 & MS & - & $2 \times M S$ & $2 \times M S$ & $5 \times M S$ \\
\hline 3 & MS & 8 & 12.50 & - & - & 25.00 & 62.50 & SRF & - & - & $2 \times M S$ & $5 \times \mathrm{MS}$ \\
\hline 4 & MS, MES & 8 & & 12.50 & - & 75.00 & 12 & - & MS & - & $6 \mathrm{xMS}$ & MS \\
\hline 5 & MS, MES & 12 & 16.67 & & - & 66.67 & 16.67 & IO, NAO & - & - & $7 \times M S, N A O$ & $2 \times N A O$ \\
\hline 6 & & 8 & 12.50 & 25.00 & 12.50 & 25.00 & 25.00 & 10 & MS, NAO & NPO & MS, NAO & $2 \times M S$ \\
\hline 7 & BAT & 15 & 13.33 & & & 26.67 & 60.00 & IO, SPO & - & - & IO, MS, SAO, SPO & $\begin{array}{c}10, \mathrm{MS}, \mathrm{NAO}, 2 \mathrm{2} \mathrm{NPO}, 2 \mathrm{xSAO}, \\
2 \times \mathrm{SPO}\end{array}$ \\
\hline 8 & DCM & 10 & 10.00 & - & 90.00 & - & - & NPO & - & $\begin{array}{l}5 \times M S, N P O \\
3 \times S A O\end{array}$ & - & - \\
\hline 9 & DCM & 11 & 36.36 & - & 63.64 & - & - & $2 \times N A O, N P O, S A O$ & - & $\begin{array}{c}3 \times 10,2 \times M S, N P O \\
\text { SAO }\end{array}$ & - & - \\
\hline 10 & & 12 & - & - & 8.33 & 50.00 & 41.67 & - & - & NAO & $\begin{array}{c}\text { IO, MS, NAO, 2xNPO, } \\
\text { SAO }\end{array}$ & IO, 2xNAO, NPO, SAO \\
\hline 11 & MES & 6 & - & - & - & 83.33 & 16.67 & - & - & - & IO, MS, NPO, 2xSAO & 10 \\
\hline 12 & NAO, MES & 6 & 16.67 & - & - & 83.33 & & NAO & - & - & $2 \times M S, 3 \times N A O$ & - \\
\hline 13 & SRF & 11 & 54.55 & 9.09 & - & 27.27 & 9.09 & IO, MS, NPO, 3xSAO & MS & - & 2xMS, NAO & MS \\
\hline 14 & BAT & 16 & 12.50 & 6.25 & 6.25 & 6.25 & 68.75 & MS, NAO & MS & MS & MS & $5 \times N A O, 3 \times N P O, 2 \times S A O, S P O$ \\
\hline 15 & SRF & 8 & 100.00 & - & - & - & - & $3 \times 10,4 \times N A O, N P O$ & - & - & - & - \\
\hline 16 & MS, SRF & 7 & 71.43 & 14.29 & - & 14.29 & - & $4 \times M S, N P O$ & MS & - & MS & - \\
\hline 17 & MS & $\overline{9}$ & & 11.11 & 33.33 & 22.22 & 33.33 & - & MS & MS, NAO, SPO & $2 \times \mathrm{MS}$ & $3 \times \mathrm{MS}$ \\
\hline 18 & MS, BAT & 8 & 12.50 & 25.00 & - & 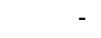 & 62.50 & 10 & $2 \times M S$ & - & - & $3 \times M S, 2 \times N A O$ \\
\hline 19 & SRF & 7 & 85.72 & 14.29 & - & - & & $2 \times 10, N A O, N P O, 2 x S A O$ & MS & - & - & - \\
\hline 20 & SRF & 15 & 73.33 & - & 6.67 & 6.67 & 13.33 & $2 \times 10,2 \times N A O, N P O, 5 \times S A O, S P O$ & - & MS & 10 & IO, NPO \\
\hline 21 & & 8 & 25.00 & - & 12.50 & 25.00 & 37.50 & IO, SPO & - & MS & MS, SAO & IO, 2xNAO \\
\hline 22 & & 17 & 23.53 & - & 5.88 & 35.29 & 35.29 & $3 \times S A O, S P O$ & - & MS & $\begin{array}{l}\text { NAO, } 2 \times N P O, S A O \\
2 \times S P O\end{array}$ & IO, MS, NAO, 3XSAO \\
\hline 23 & SRF & 8 & 75.00 & 12.50 & - & 12.50 & & $10,2 x M S, N A O, N P O, S P O$ & MS & - & MS & \\
\hline 24 & MS, MES & 13 & 15.38 & 7.69 & - & 61.54 & 15.38 & $2 \times M S$ & MS & - & IO, 4xMS, 3xNAO & NAO, NPO \\
\hline 25 & & 14 & 28.57 & 7.14 & 14.29 & 7.14 & 42.86 & $2 \times M S, 2 \times N A O$ & MS & $2 \times M S$ & NAO & MS, 3xNPO, 2xSAO \\
\hline 26 & SRF & 7 & 85.72 & 14.29 & - & - & - & $\begin{array}{c}\text { 2xIO-SRF, MS-EPI, 2xNAO-SRF, } \\
\text { 2xNPO-SRF }\end{array}$ & $\begin{array}{c}\text { 2xIO-SRF, MS-EPI, 2xNAO-SRF, } \\
\text { 2xNPO-SRF }\end{array}$ & - & - & - \\
\hline 27 & SRF & 11 & 100.00 & - & - & - & - & $2 \times 10, N A O, 4 x N P, 4 x S P O$ & - & - & - & - \\
\hline 28 & MS & 11 & 9.09 & 27.27 & - & 36.36 & 27.27 & MS & $3 \times N A O$ & - & $4 \mathrm{xMS}$ & $3 \times M S$ \\
\hline 29 & & 12 & 50.00 & & 16.67 & 16.67 & 16.67 & IO, MS, 3XNAO, SAO & - & MS, NAO & $2 \times M S$ & $2 \times M S$ \\
\hline 30 & & 6 & 50.00 & - & 16.67 & 16.67 & 16.67 & IO, NAO, SPO & - & MS & NPO & IO-BAT \\
\hline 31 & MS & 28 & 25.00 & 10.71 & 7.14 & 35.71 & 21.43 & $4 \times 10,2 \times M S, S A O$ & $3 \times M S$ & $2 \times M S$ & $6 \mathrm{xMS}, 2 \times \mathrm{NAO}, 2 \mathrm{xNPO}$ & IO, 2xMS, 3xNAO \\
\hline 32 & SRF & 6 & 100.00 & 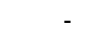 & - & & & IO, 2xNA, NPO, 2xSAO & - & - & - & - \\
\hline 33 & SRF & 6 & 100.00 & - & - & - & - & NAO, 3xNPO, SAO, SPO & - & - & - & - \\
\hline 34 & SRF & 14 & 100.00 & & - & - & 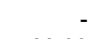 & $10,4 \times N A O, 5 \times N P O, 2 \times S A O, 2 \times S P O$ & - & - & - & - \\
\hline 35 & SRF & 13 & 69.23 & 7.69 & - & - & 23.08 & $4 \times 10,3 \times N A O, S A O, S P O$ & MS & - & - & $3 x M S$ \\
\hline 36 & SRF & 7 & 100.00 & . & - & & & $3 \times 10,3 x N P O$, SAO & - & - & - & - \\
\hline- & & 24 & 41.67 & - & 12.50 & 29.17 & 16.67 & $2 x \mid O, M S, 2 x N A O, 3 x N P O, 2 x S A O$ & - & $\mathrm{MS}, 2 \mathrm{xNAO}$ & $2 \times 10,4 \times M S, N P O$ & $\mathrm{MS}, \mathrm{NAO}, \mathrm{NPO}, \mathrm{SAO}$ \\
\hline
\end{tabular}

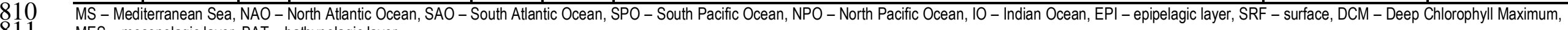

811 MES - mesopelagic layer, BAT - bathypelagic layer 
812 Supplementary Table 4 Number of edges within each region and depth layer before $(\mathrm{J}>0 \%)$ and after filtering edges with low Jaccard 813 index measuring how often the association partners appeared together in the region and depth layer. The DCM layer in the South

814 Pacific Ocean (SPO) contained only one subnetwork, which resulted in the edge prevalence being $100 \%$ for all edges.

\begin{tabular}{|c|c|c|c|c|c|c|c|c|c|}
\hline Region & Layer & Samples & Depth (m) & $\mathrm{J}>0 \%$ & $\mathrm{~J}>10 \%$ & $\mathrm{~J}>\mathbf{2 0 \%}$ & $\mathrm{J}>30 \%$ & $\mathrm{~J}>40 \%$ & $\mathrm{~J}>50 \%$ \\
\hline \multirow[t]{5}{*}{$\mathrm{MS}$} & EPI - SRF & 19 & 3 & 3710 & 3631 & 3263 & 2881 & 2375 & 1797 \\
\hline & EPI & 18 & $12-50$ & 4763 & 4682 & 4196 & 3731 & 3064 & 2189 \\
\hline & EPI - DCM & 21 & $40-130$ & 5545 & 5417 & 4736 & 4030 & 3062 & 2027 \\
\hline & MES & 52 & $200-1000$ & 8756 & 8403 & 7336 & 6179 & 4629 & 3088 \\
\hline & BAT & 35 & $1100-3300$ & 4497 & 4263 & 3694 & 3171 & 2506 & 1830 \\
\hline \multirow[t]{5}{*}{ NAO } & EPI - SRF & 34 & 3 & 15862 & 15255 & 13478 & 11449 & 8487 & 5331 \\
\hline & EPI & 4 & 50 & 3027 & 3027 & 3027 & 2778 & 2529 & 2091 \\
\hline & EPI - DCM & 6 & $70-106$ & 3865 & 3865 & 3738 & 3480 & 2973 & 2212 \\
\hline & MES & 14 & $200-800$ & 6325 & 6289 & 5689 & 5109 & 4169 & 2978 \\
\hline & BAT & 20 & $1200-4539$ & 7490 & 7419 & 6831 & 6206 & 5211 & 3857 \\
\hline \multirow[t]{4}{*}{ SAO } & EPI - SRF & 26 & 3 & 13118 & 12768 & 11026 & 9269 & 6842 & 4353 \\
\hline & EPI - DCM & 4 & $80-130$ & 4199 & 4199 & 4199 & 3941 & 3443 & 2468 \\
\hline & MES & 6 & $450-850$ & 3937 & 3937 & 3740 & 3440 & 2687 & 1614 \\
\hline & BAT & 11 & $1290-4000$ & 4143 & 4130 & 3886 & 3605 & 3049 & 2254 \\
\hline \multirow[t]{4}{*}{ NPO } & EPI - SRF & 29 & 3 & 14376 & 13778 & 11919 & 9907 & 7323 & 4736 \\
\hline & EPI - DCM & 3 & $37-110$ & 3100 & 3100 & 3100 & 3100 & 2568 & 1968 \\
\hline & MES & 9 & $200-780$ & 4197 & 4197 & 3781 & 3343 & 2583 & 1625 \\
\hline & BAT & 12 & $2000-4000$ & 5198 & 5185 & 4834 & 4510 & 4009 & 3372 \\
\hline \multirow[t]{4}{*}{ SPO } & EPI - SRF & 14 & $3-5$ & 12007 & 11927 & 10420 & 8990 & 6728 & 4480 \\
\hline & EPI - DCM & 1 & 65 & 1530 & 1530 & 1530 & 1530 & 1530 & 1530 \\
\hline & MES & 3 & $450-650$ & 2066 & 2066 & 2066 & 2066 & 1756 & 1318 \\
\hline & BAT & 3 & $1500-4000$ & 3159 & 3159 & 3159 & 3159 & 2906 & 2128 \\
\hline \multirow[t]{4}{*}{10} & EPI - SRF & 35 & 3 & 14307 & 13646 & 11736 & 9602 & 6912 & 4396 \\
\hline & EPI - DCM & 3 & $86-130$ & 3411 & 3411 & 3411 & 3411 & 2855 & 2310 \\
\hline & MES & 7 & $400-950$ & 4654 & 4654 & 4344 & 3961 & 3083 & 2082 \\
\hline & BAT & 8 & $1065-4000$ & 2928 & 2928 & 2790 & 2563 & 2101 & 1290 \\
\hline
\end{tabular}

815 MS - Mediterranean Sea, NAO - North Atlantic Ocean, SAO - South Atlantic Ocean, SPO - South Pacific Ocean, NPO - North Pacific 816 Ocean, IO - Indian Ocean, EPI - epipelagic layer, SRF - surface, DCM - Deep Chlorophyll Maximum, MES - mesopelagic layer, BAT 817 - bathypelagic layer 


\section{SUPPLEMENTARY MATERIAL}

821 Supplementary Material 1: Highly prevalent (>70\%) regional associations. For each association 822 between two ASVs (first and second column) we list: region (third column), depth layer (fourth 823 column), prevalence in that region and depth layer (fifth column), type: eukaryotic (Euk_Euk), 824 prokaryotic (Prok_Prok), and association between domains (Euk_Prok) (sixth column), and the phyla 825 (seventh and eight column).

827 Supplementary Material 2: Associations appearing in all layers in at least one region. For each 828 association between two ASVs (first and second column) we list: the classification in each layer (3-6 829 column), overall prevalence (8. column), prevalence in each region and depth layer (9-34. column), 830 the number of regions in which the association appeared in all layers (AllLayers, 35. column), the 831 number of layers an association appears in a region (36-41. column), type: eukaryotic (Euk_Euk), 832 prokaryotic (Prok_Prok), and association between domains (Euk_Prok) (42. column), and the phyla 833 (43-44. column). 

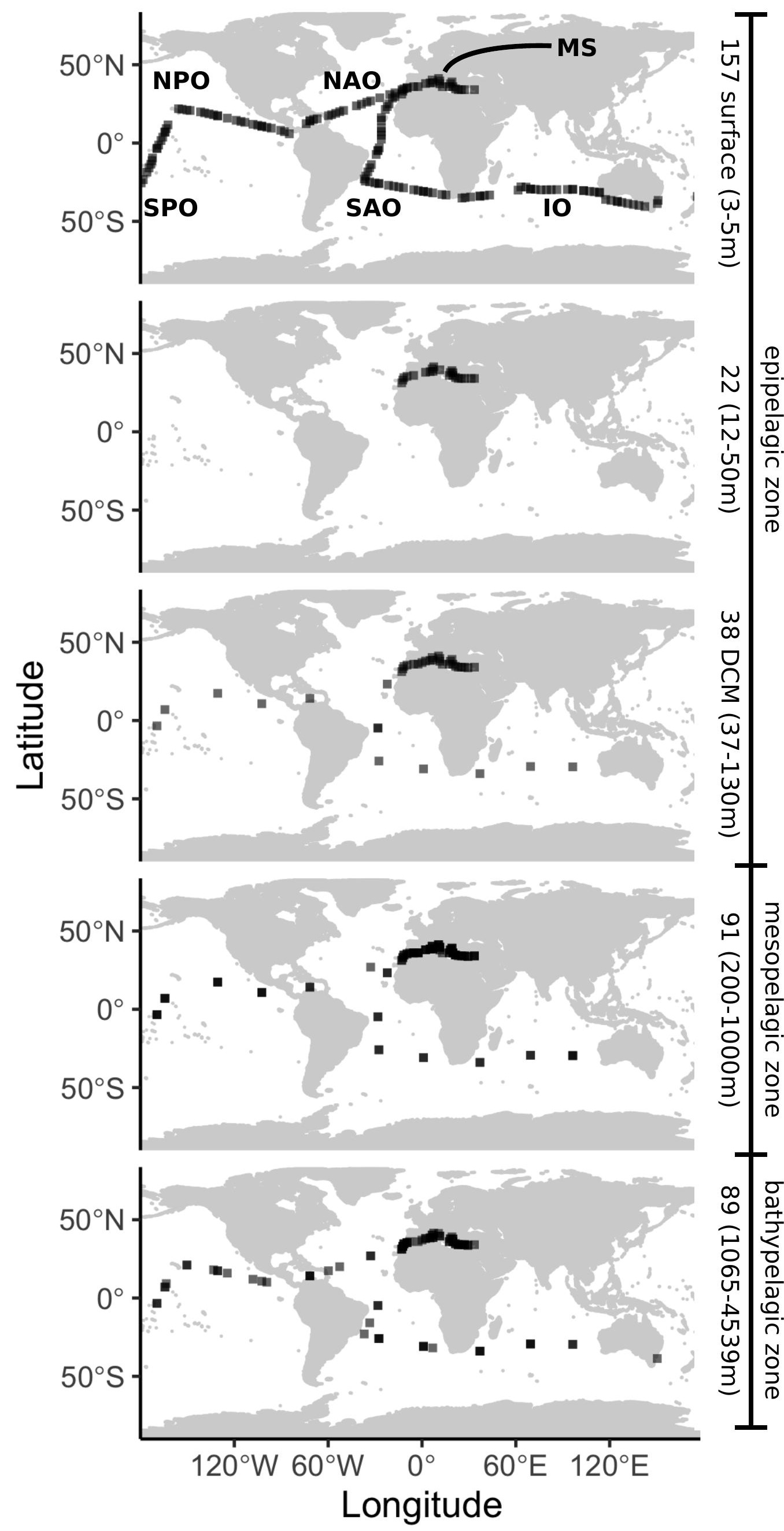

MS - Mediterranean Sea

IO - Indian Ocean

NAO - North Atlantic Ocean
NPO - North Pacific Ocean SAO - South Atlantic Ocean SPO - South Pacific Ocean 
Mediterranean North Atlantic South Atlantic South Pacific North Pacific

\author{
Indian
}

Sea (MS) Ocean (NAO) Ocean (SAO) Ocean (SPO) Ocean (NPO) Ocean (IO)
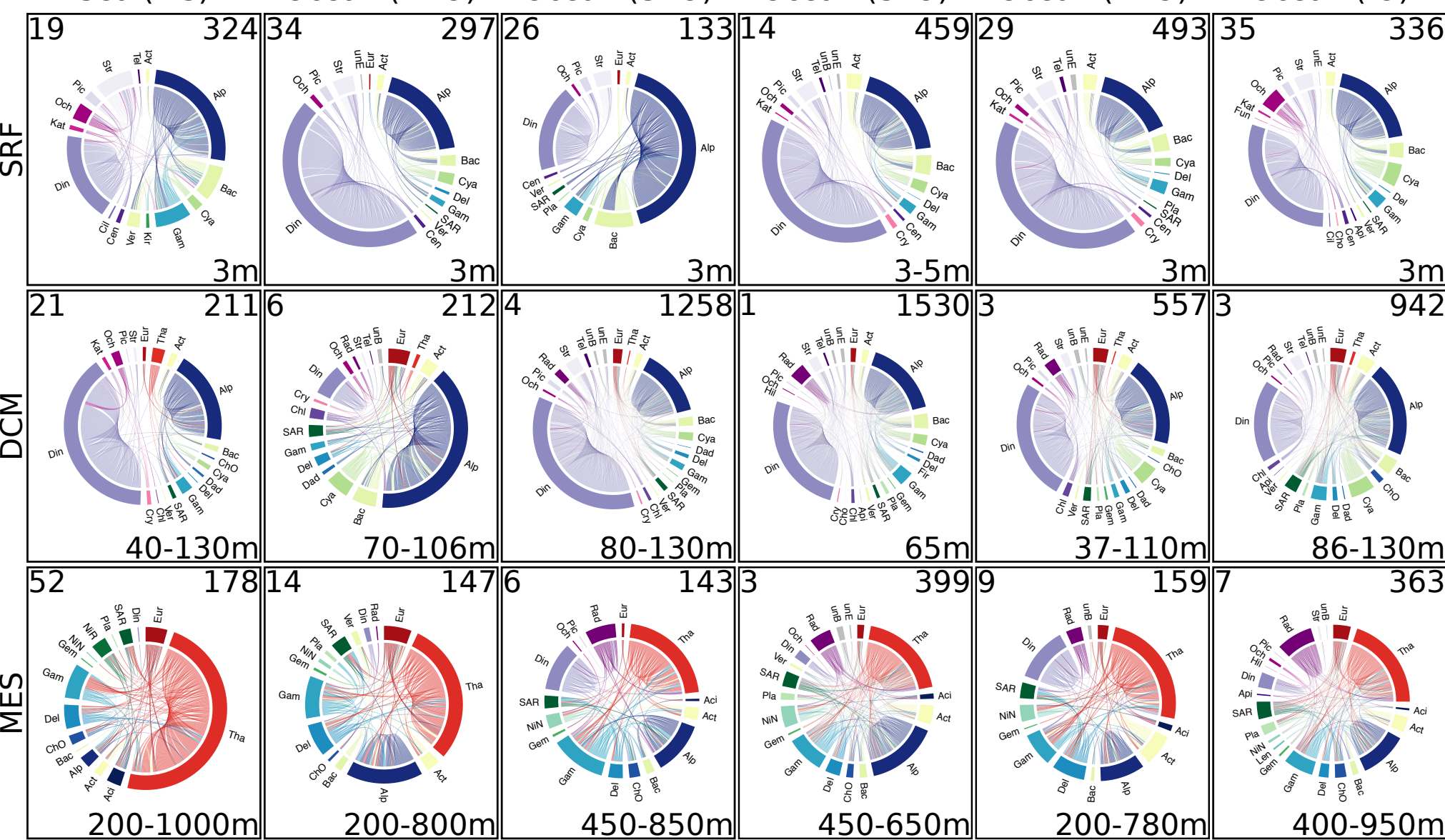

\begin{tabular}{|r}
$86-130 m$ \\
$7 \quad 363$
\end{tabular}

$\frac{1}{\infty}$
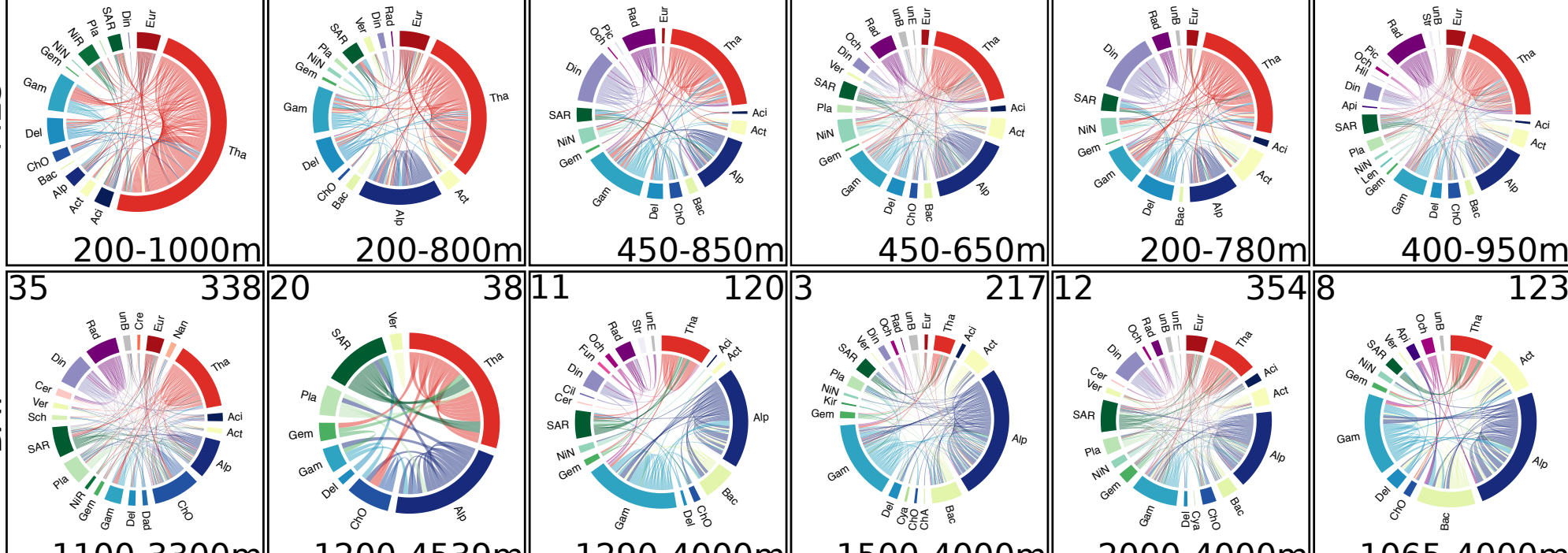

$1100-3300 \mathrm{~m}$

$1200-4539 m$

$1290-4000 \mathrm{~m}$

$1500-4000 \mathrm{~m}$

2000-4000m

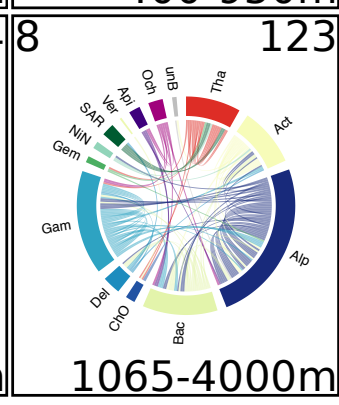

\section{Archaea}

Crenarchaeota

Euryarchaeota Nanoarchaeaeota

Thaumarchaeota

\section{Bacteria}

Acidobacteria
Actinobacteria
Alphaproteobacteria
Bacteroidetes
Calditrichaeota
ChA - Chlamydiae
ChO - Chloroflexi
Cyanobacteria
Dadabacteria
Deinococcus-Thermus
Deltaproteobacteria
Firmicutes

Gammaproteobacteria
Gemmatimonadetes
Hydrogenedentes
Kiritimatiellaeota
Lentisphaerae
Margulisbacteria
NiN - Nitrospinae
NiR - Nitrospirae
Planctomycetes
SAR406 clade (Marinimicrobia)
Schekmanbacteria
Spirochaetes
Verrucomicrobia

Eukaryota

Apicomplexa Apusomonadidae Centroheliozoa Cercozoa

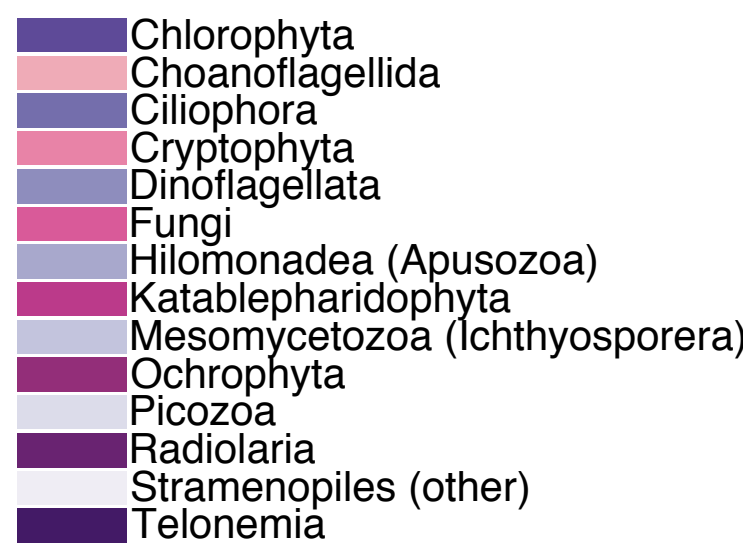

Unknown

unBac

noProk

unEuk 
B)

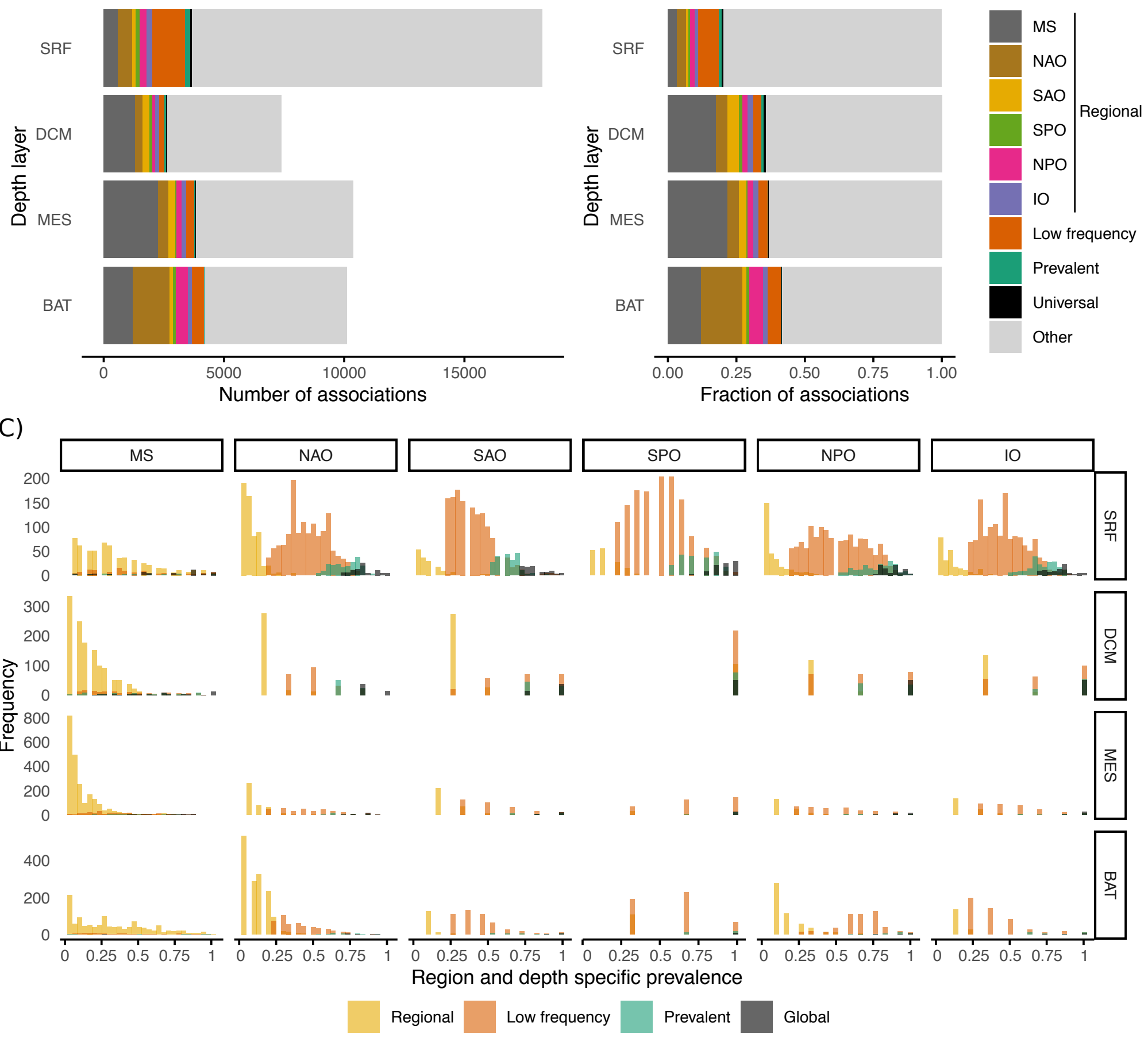

$\frac{\grave{D}}{\frac{1}{0}}$

BAT

200

150

100

50

300

200

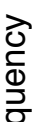

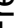

400
Region and depth specific prevalence
Prevalent 
SRF $\square$

DCM \

MES पI

BAT

SRF $\square$

$\mathrm{DCM}$

MES 매

BAT

RF $\square$

1

ए।

崩

SRF

DCM प

MES L

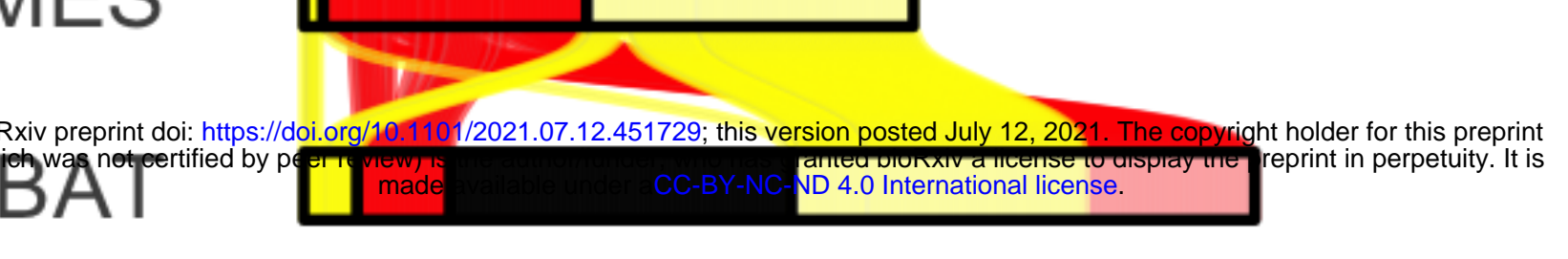

SRF $\square$

DCM प1口

MES I

BAT II —

SRF $\square$

DCM

MES

BAT

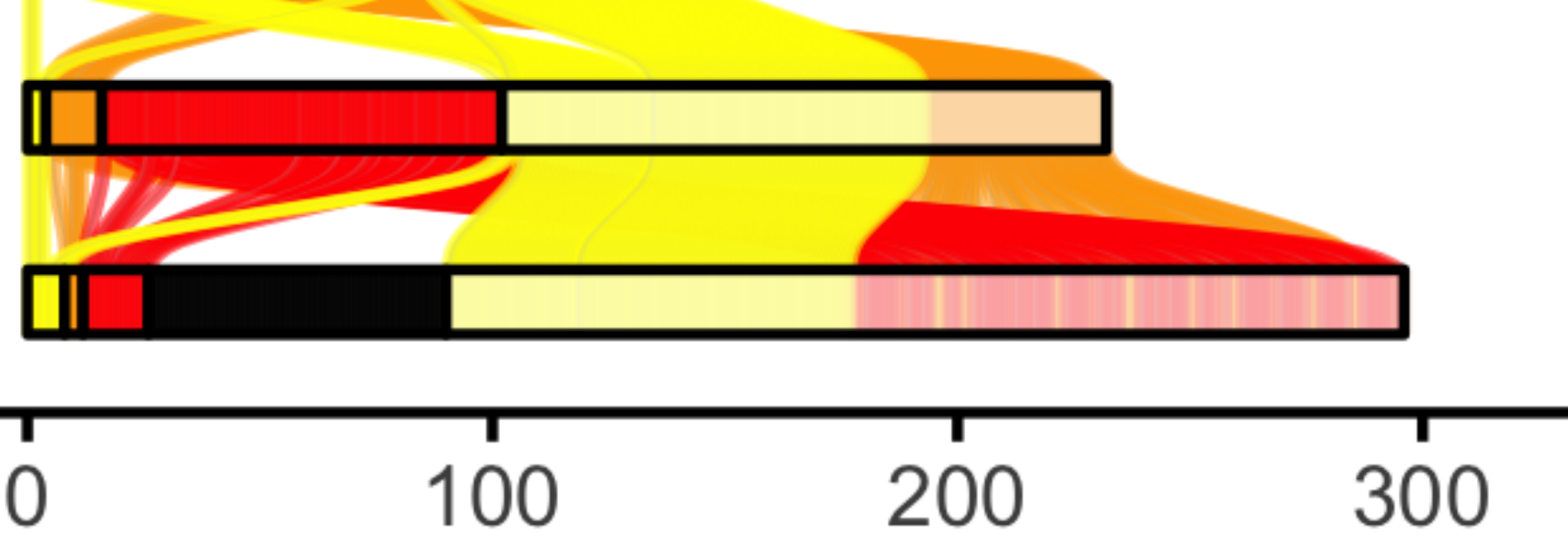

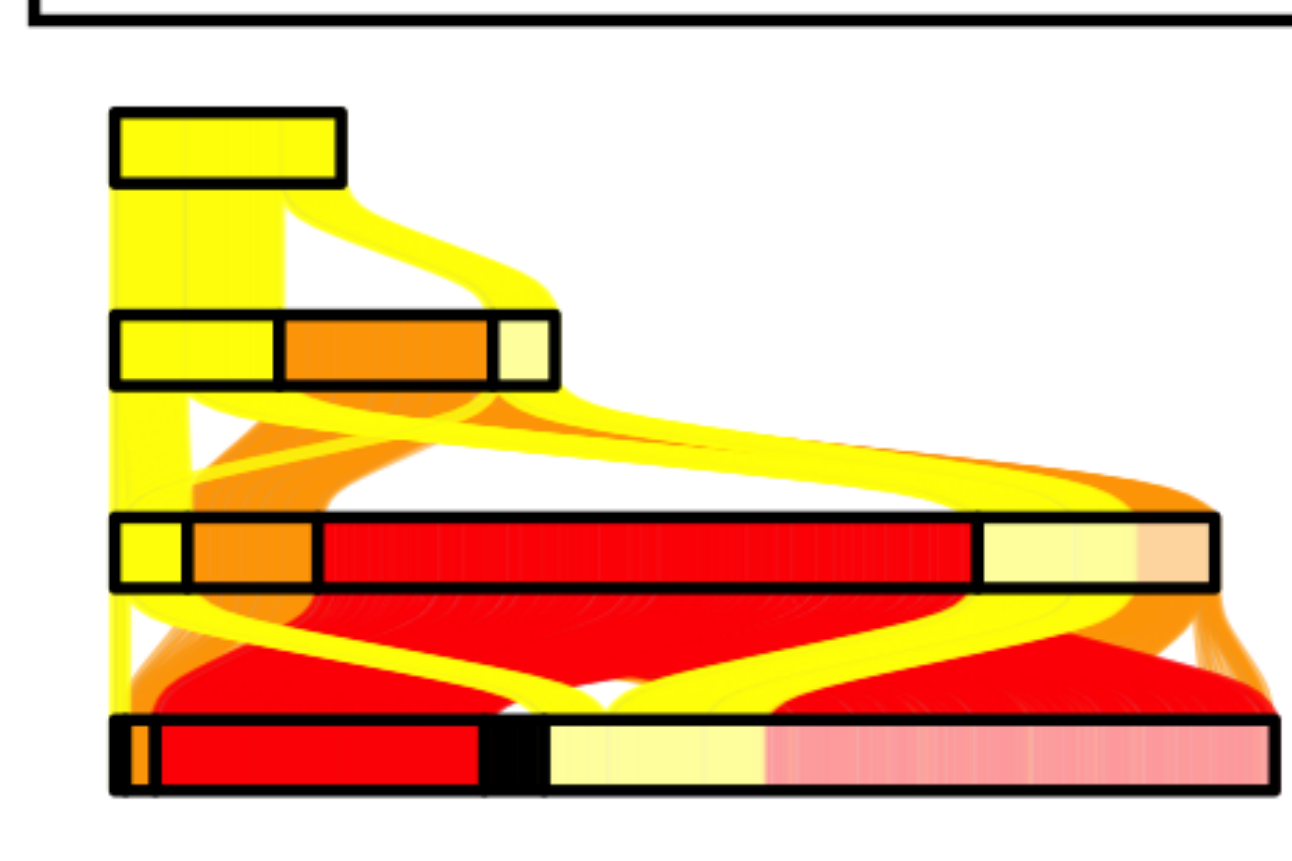

$\square$

1
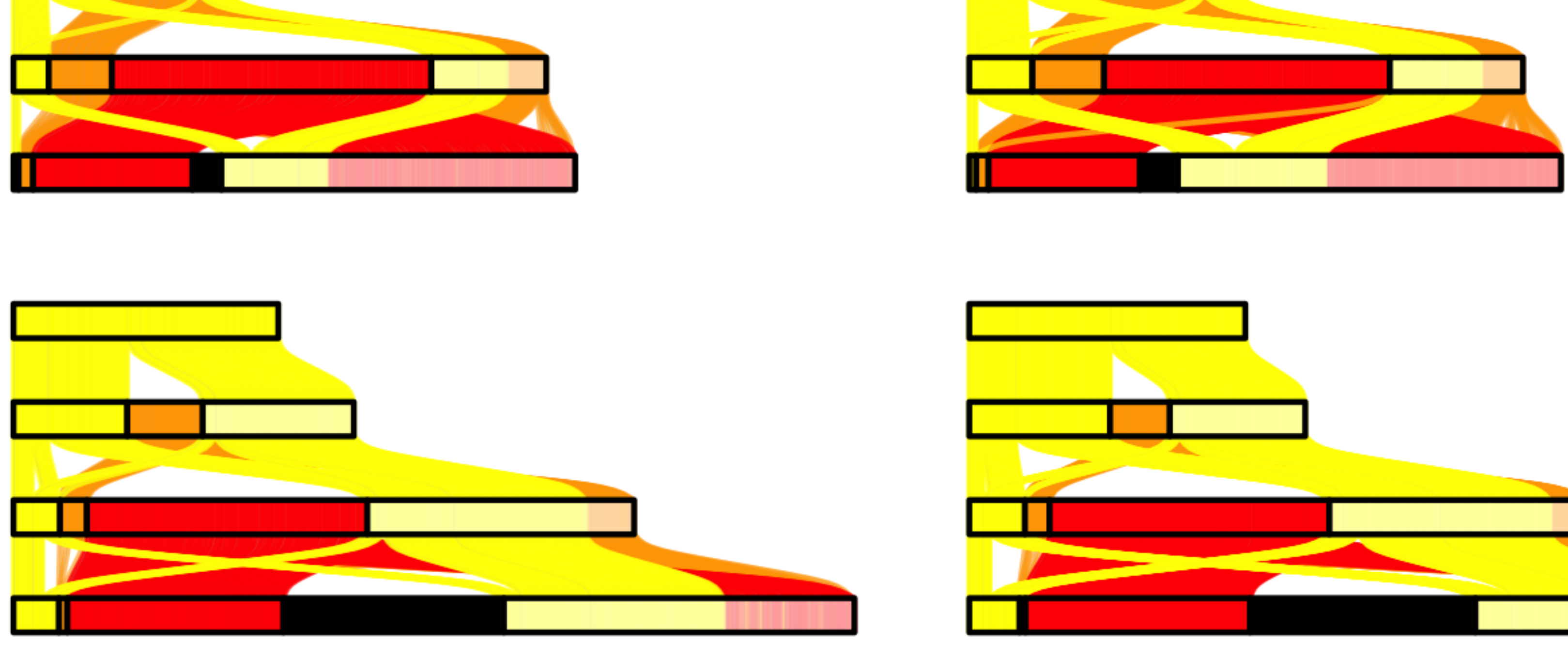

$\square$

प1

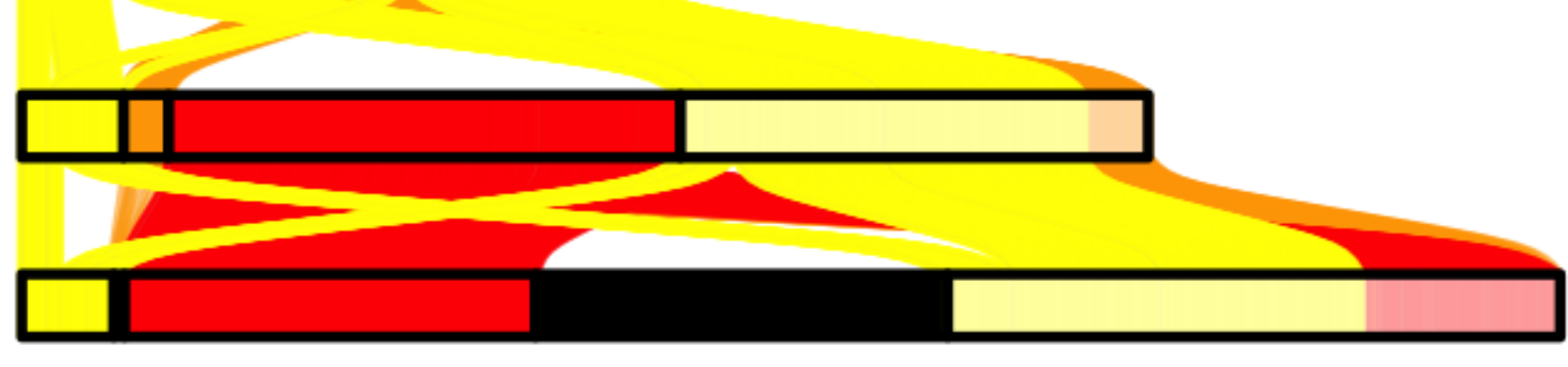

$\square$

1

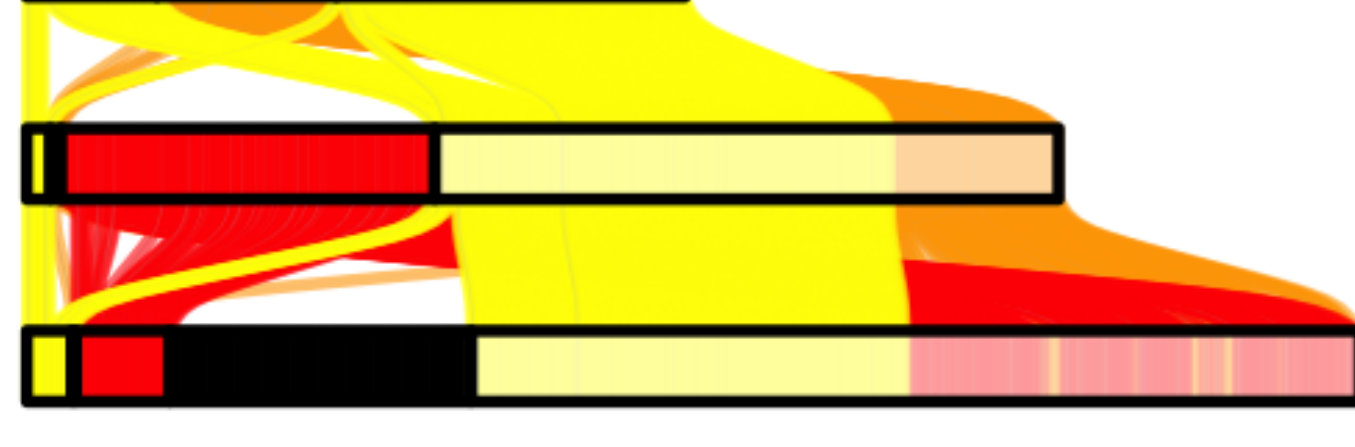

$\square$

묘

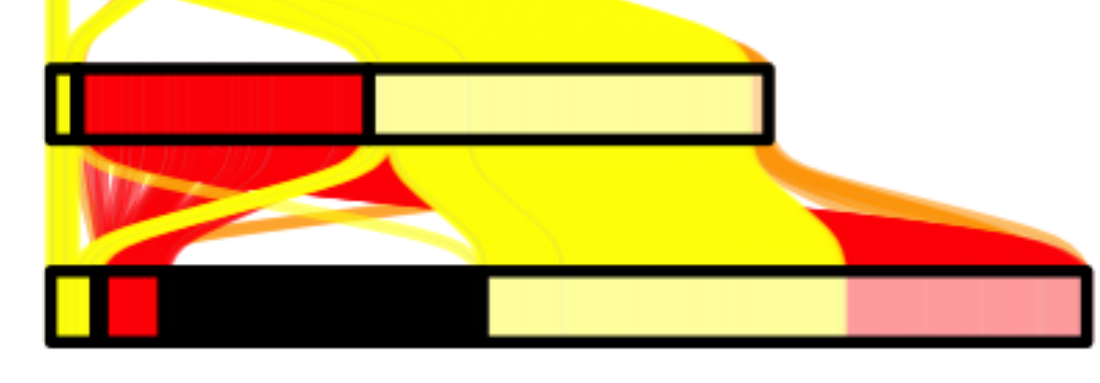

$\square$

II

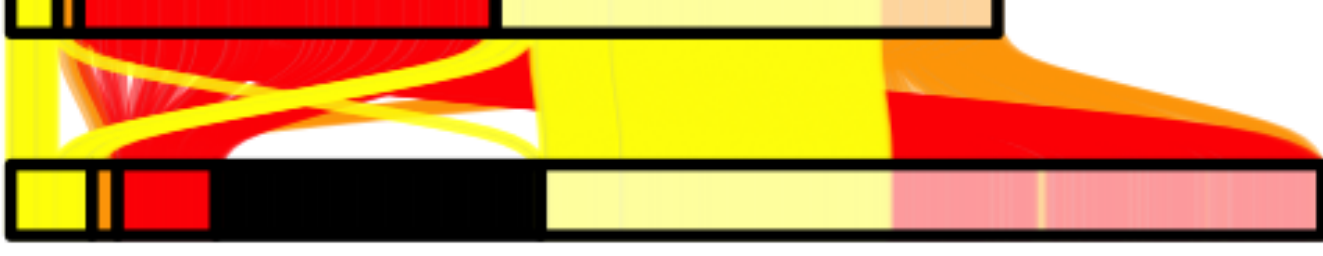

$\square$

$\square$

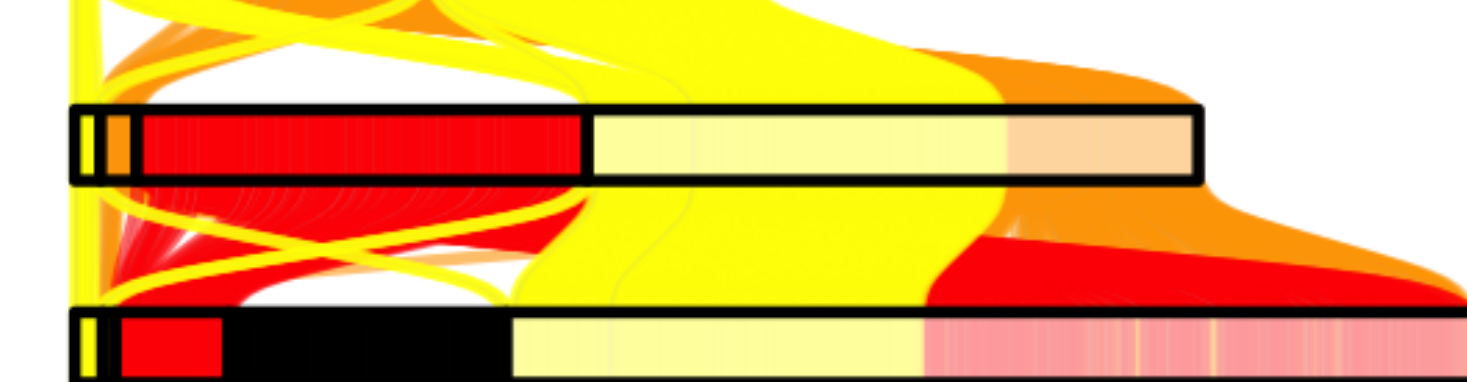

$\square$

1

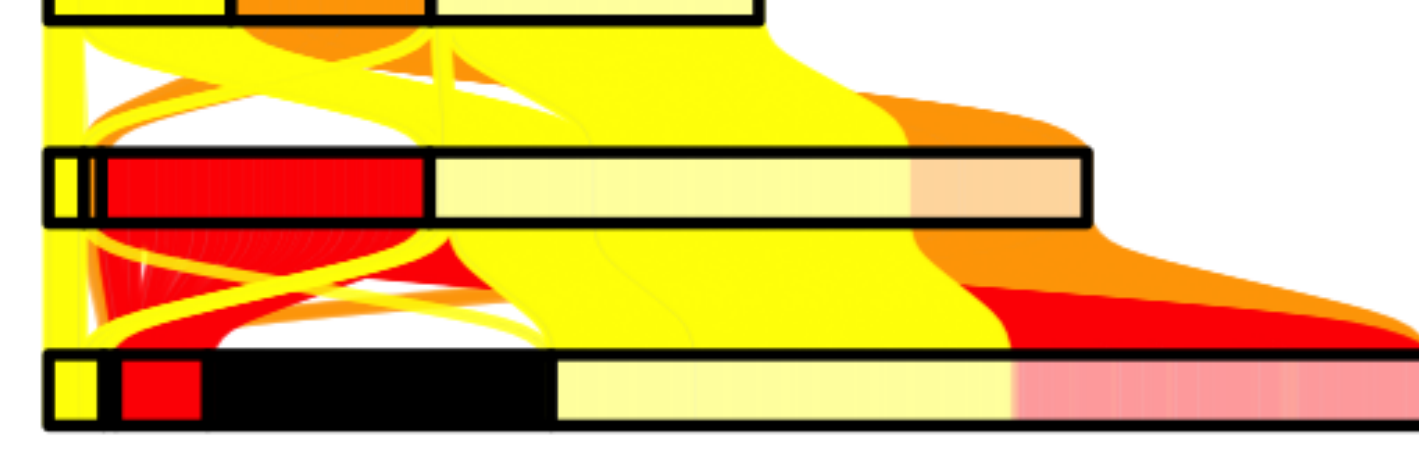

$\square$

미미

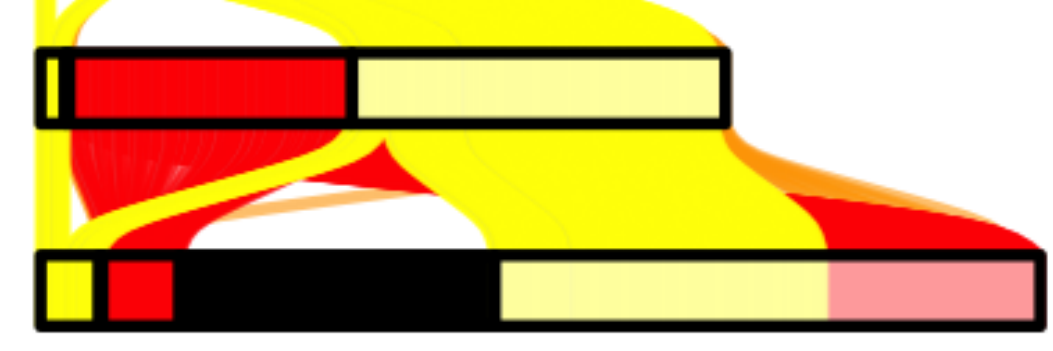

$\square$

$\square$

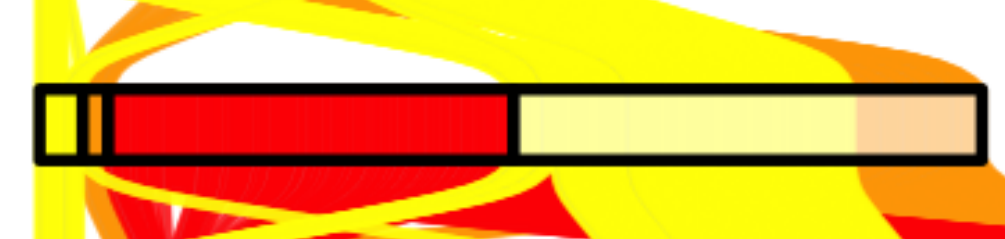

$\square$

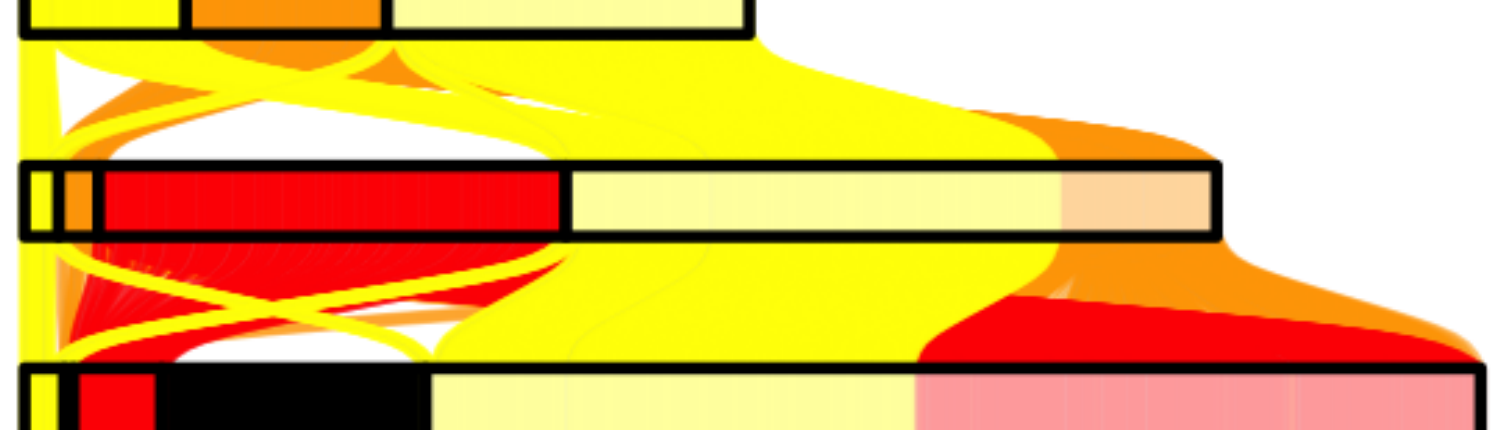

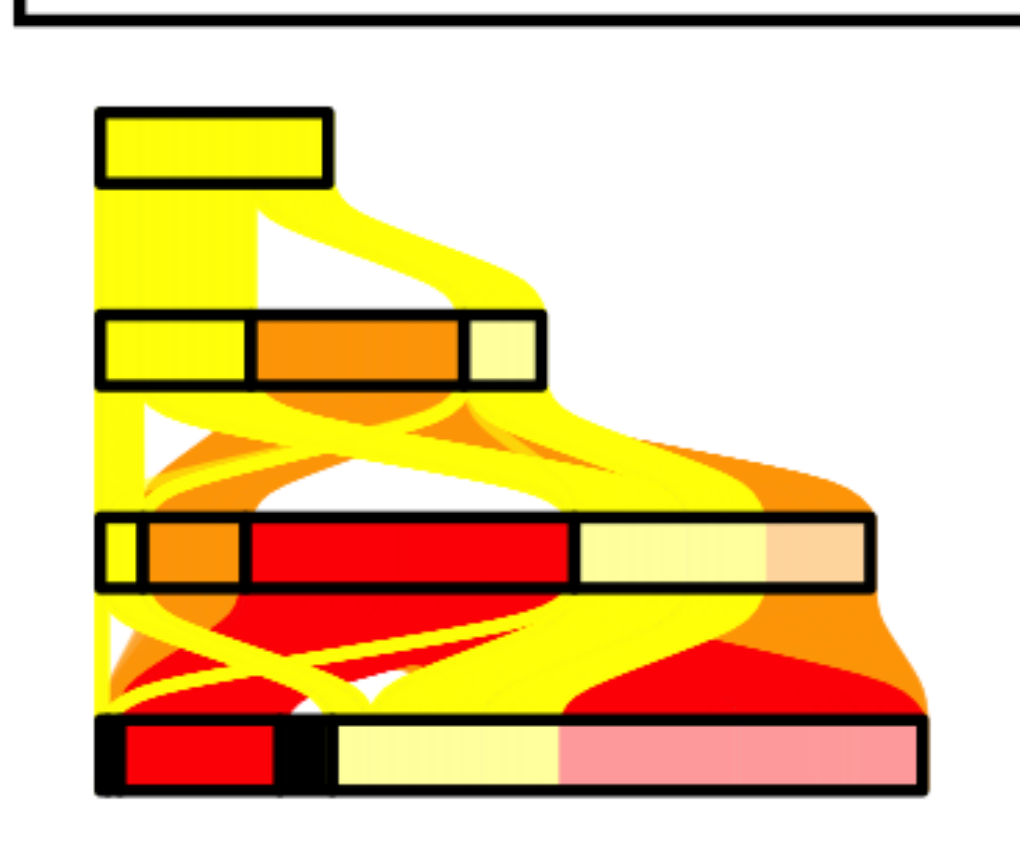
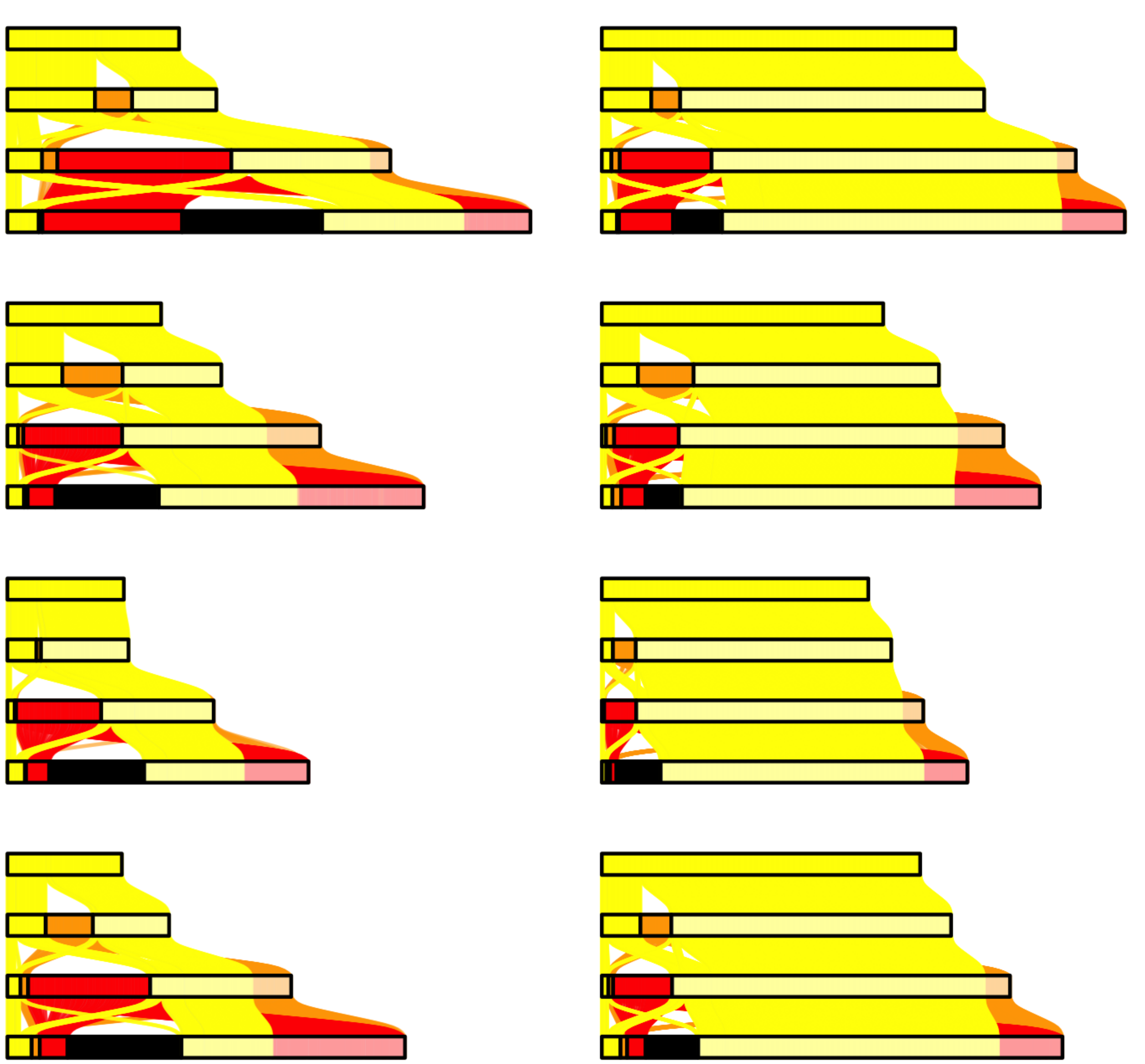

$\square$

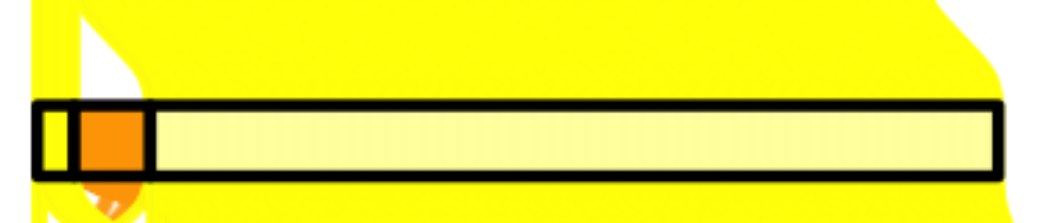
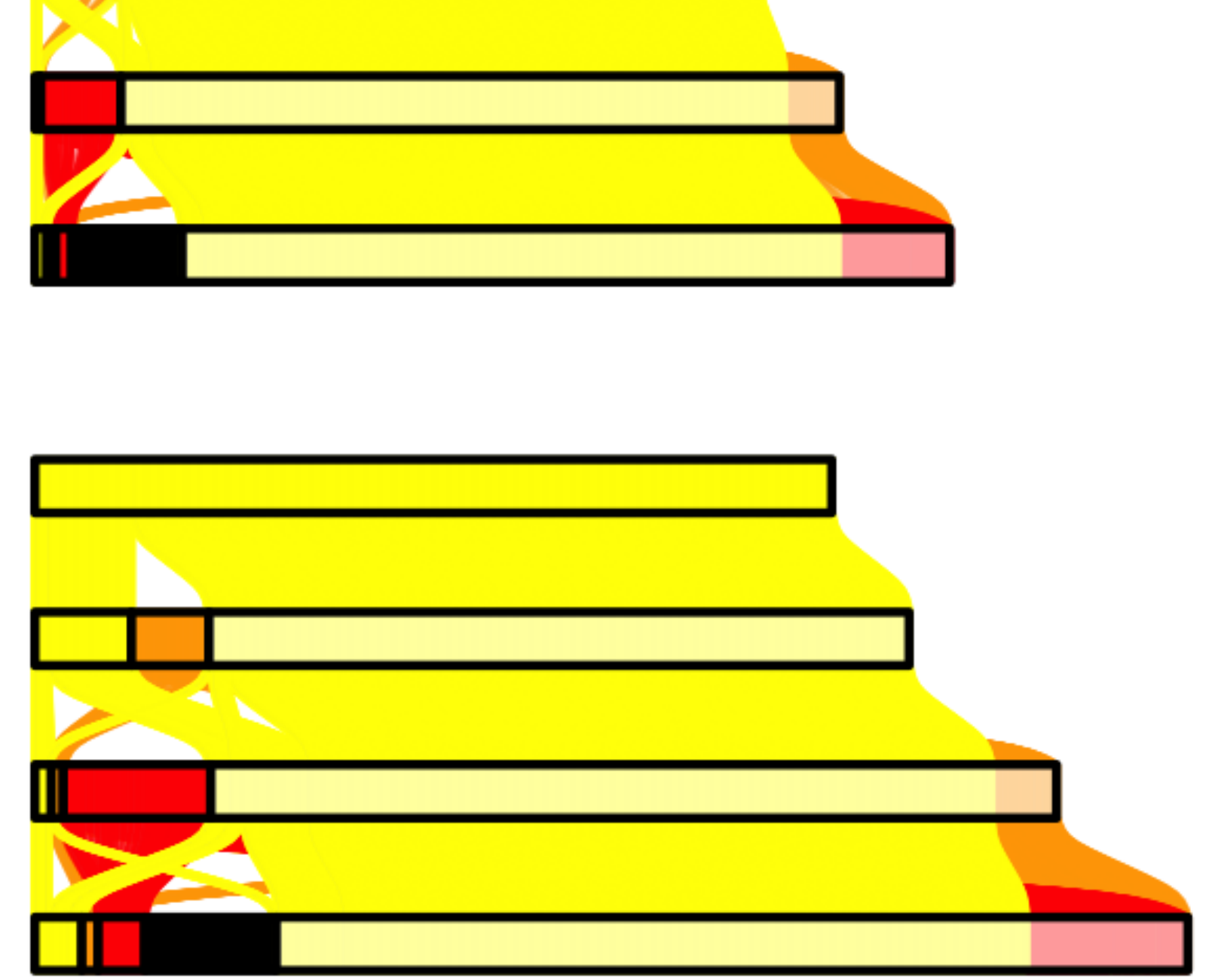

$\square$
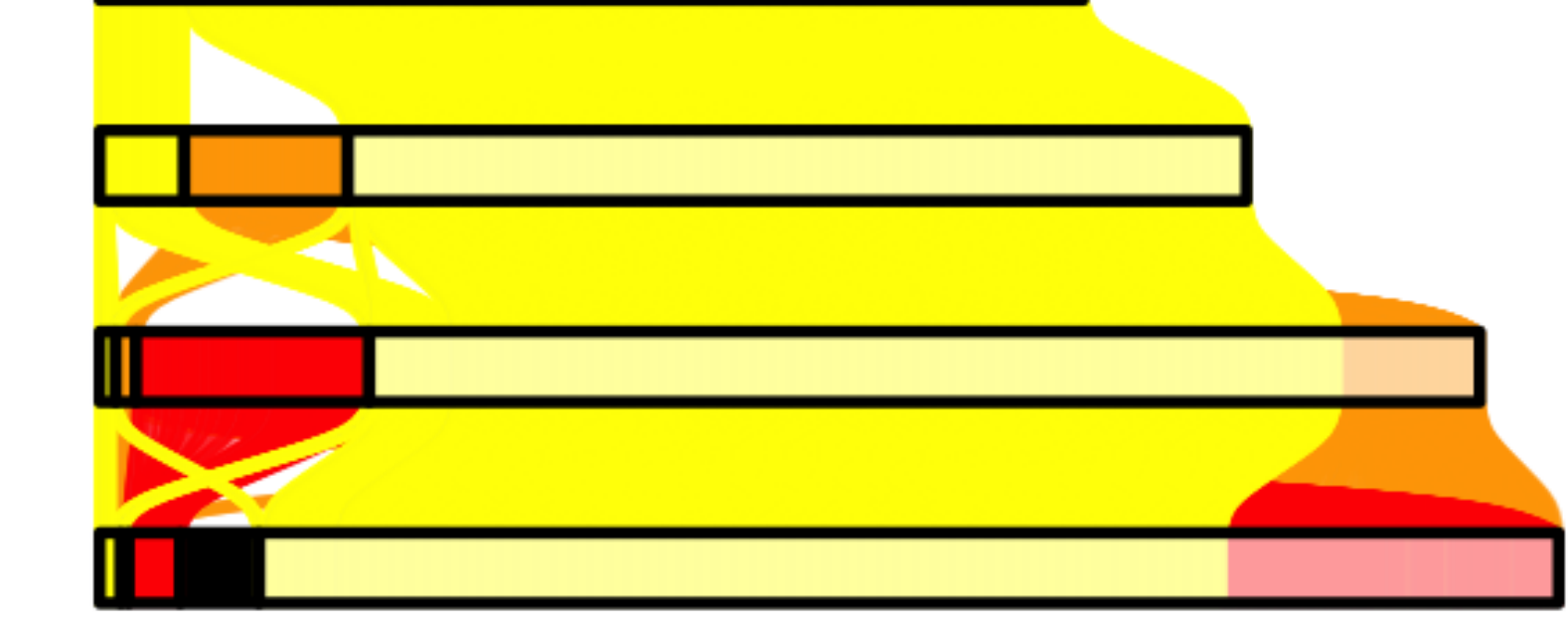

$\square$
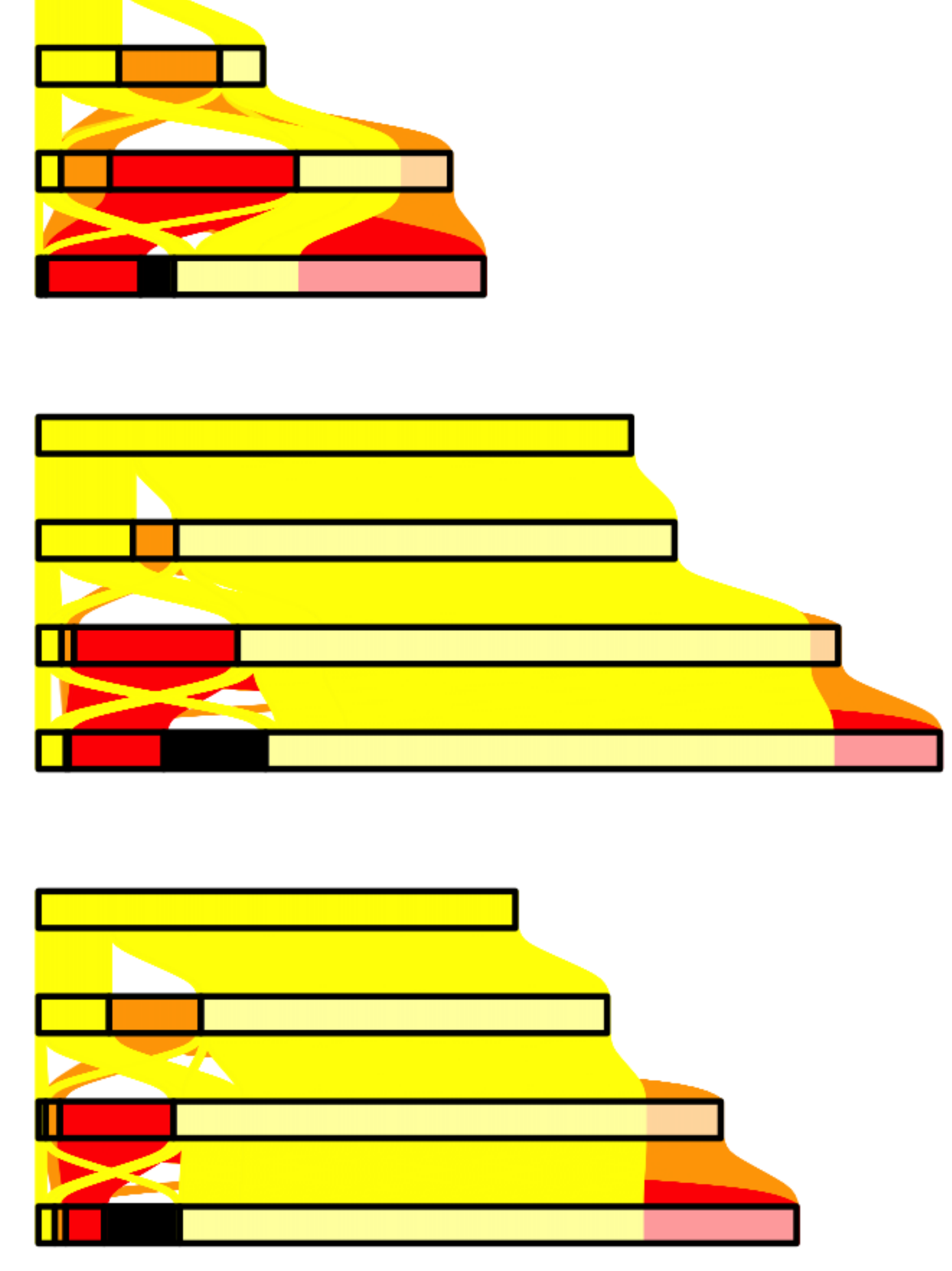

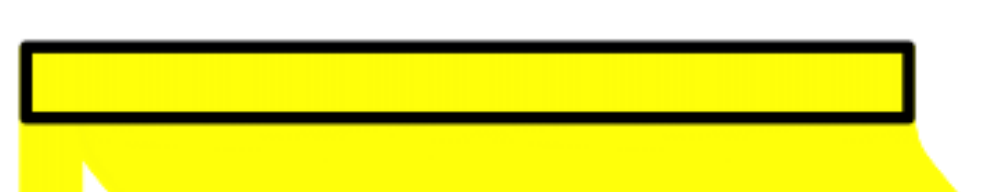

एب
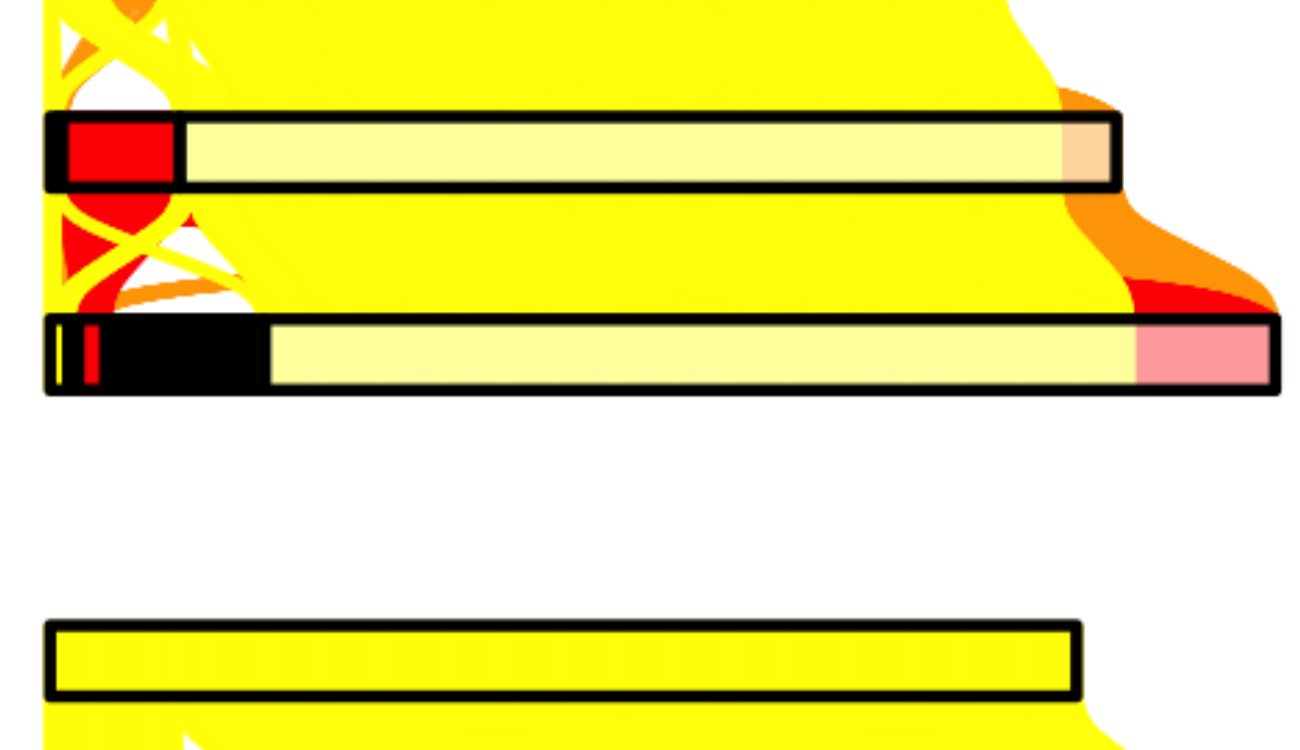

पा

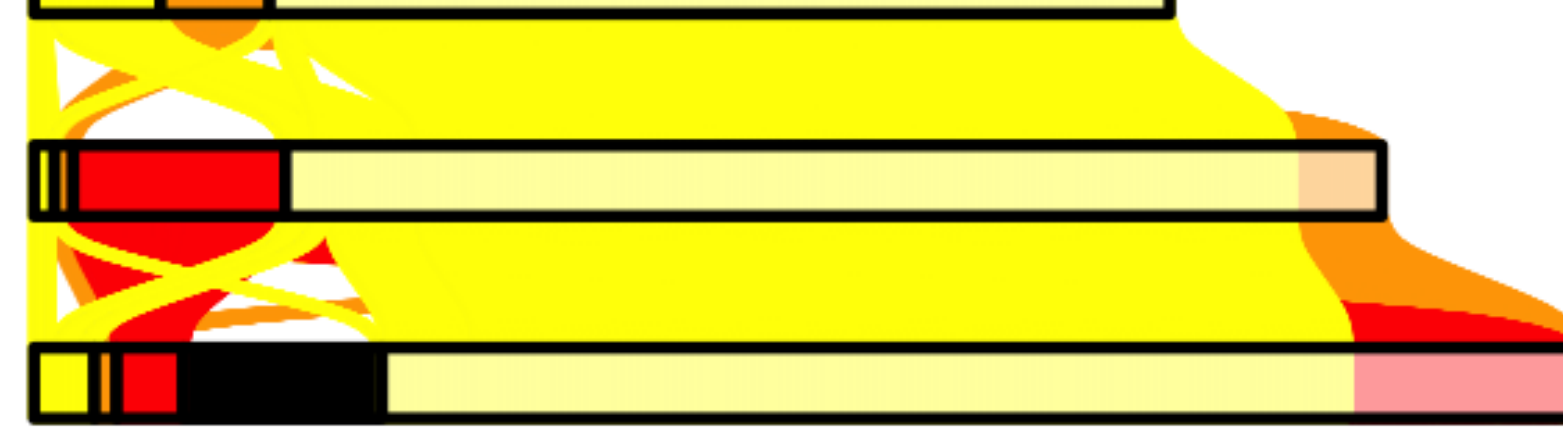

$\square$
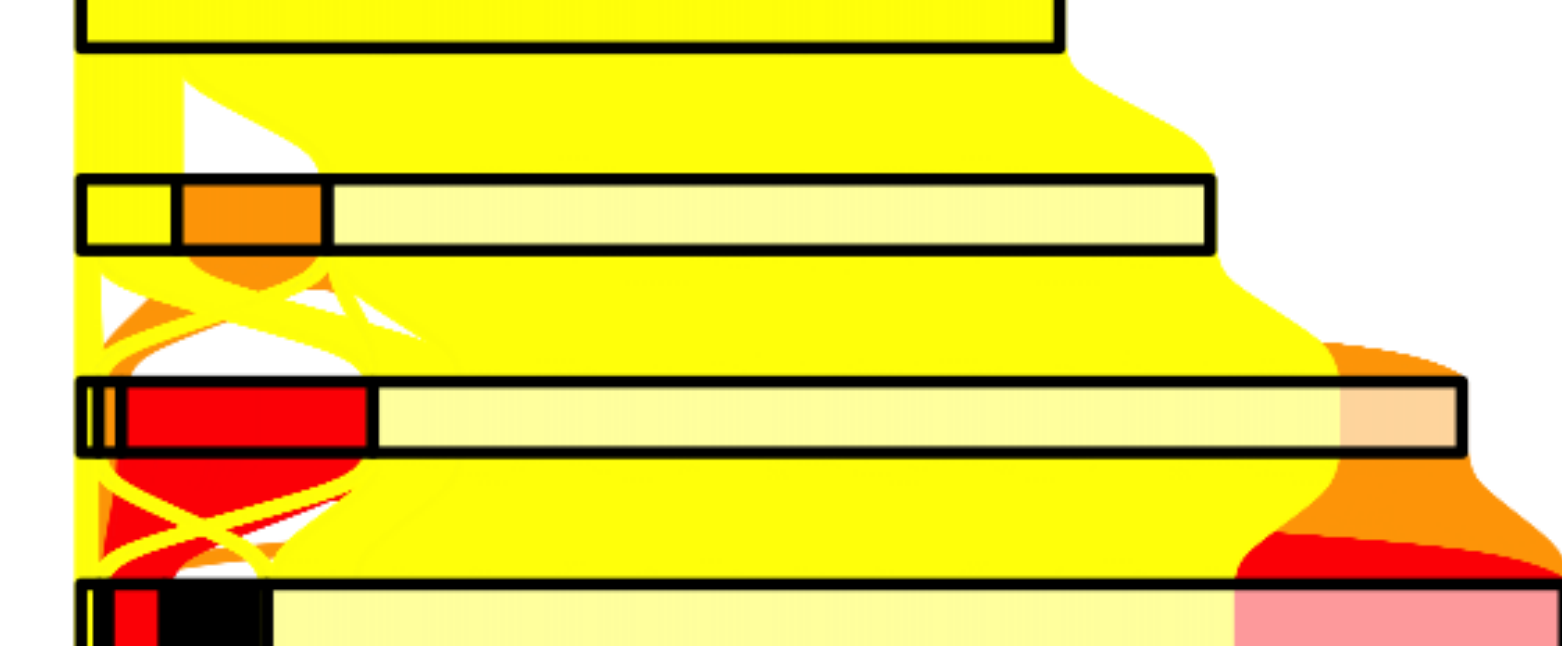

$\begin{array}{llll}1000 & 2000 & 3000 & 4000\end{array}$

Frequency

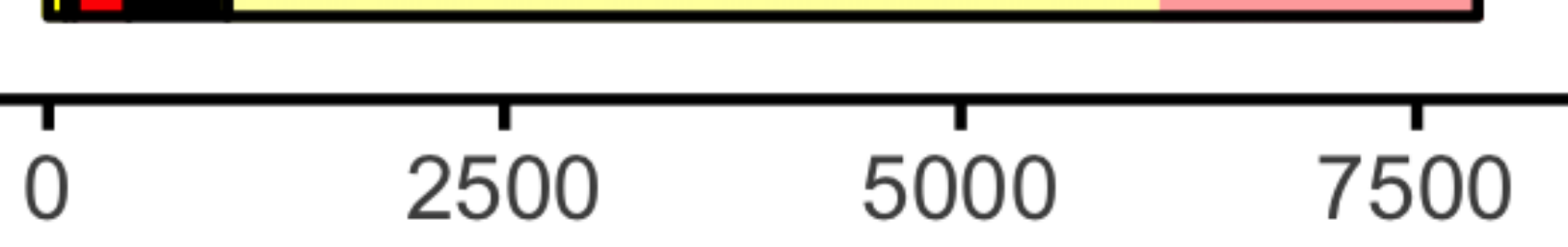
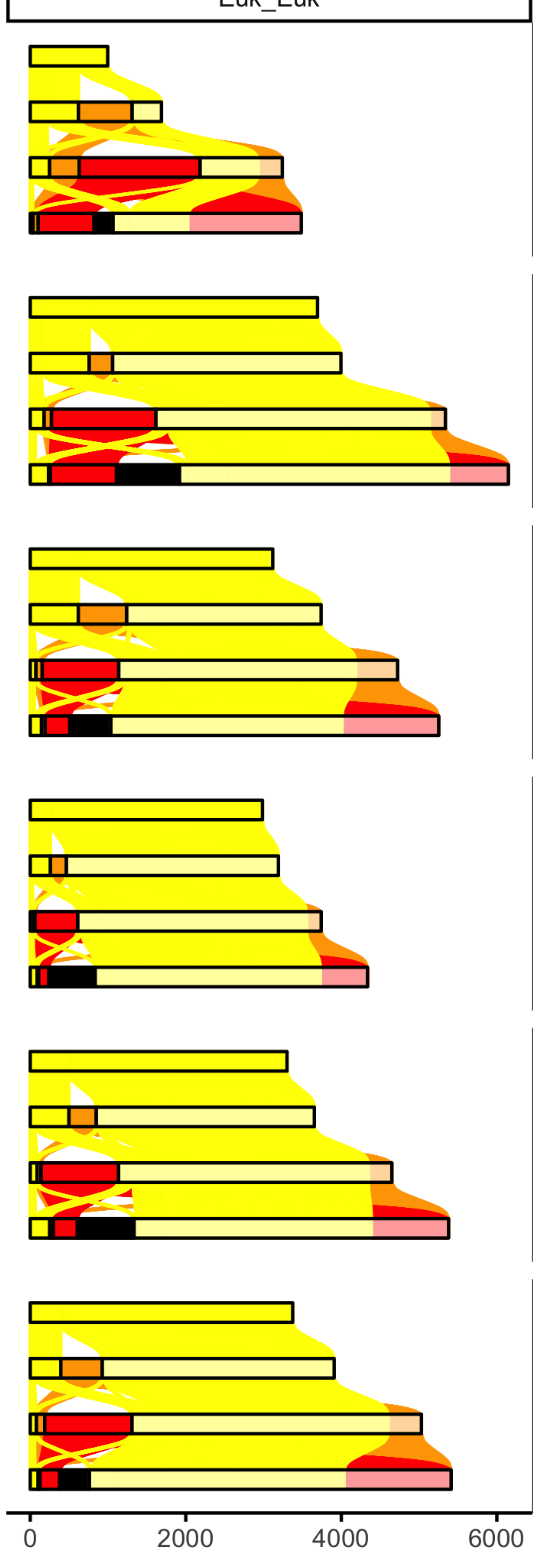

bathypelagic $\square$ absent 


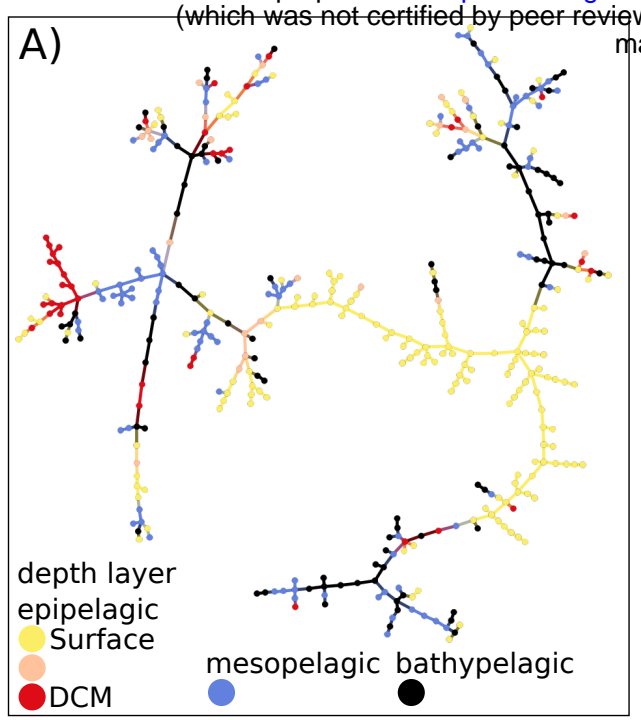

B)

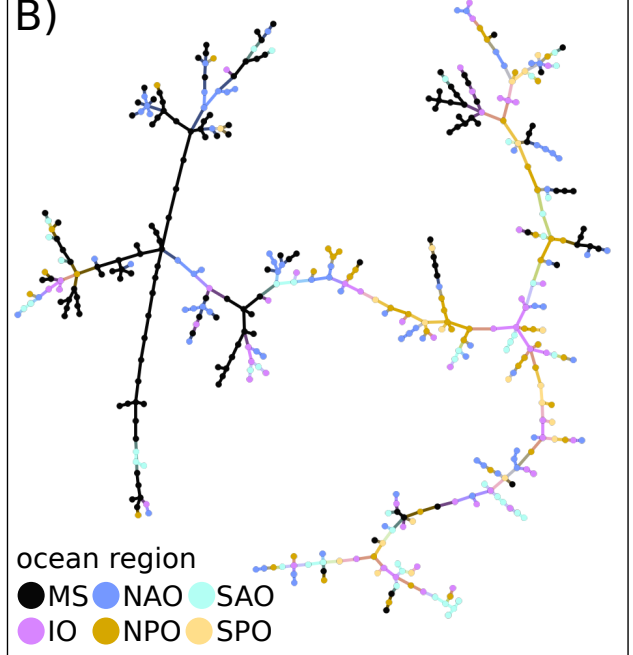

D)
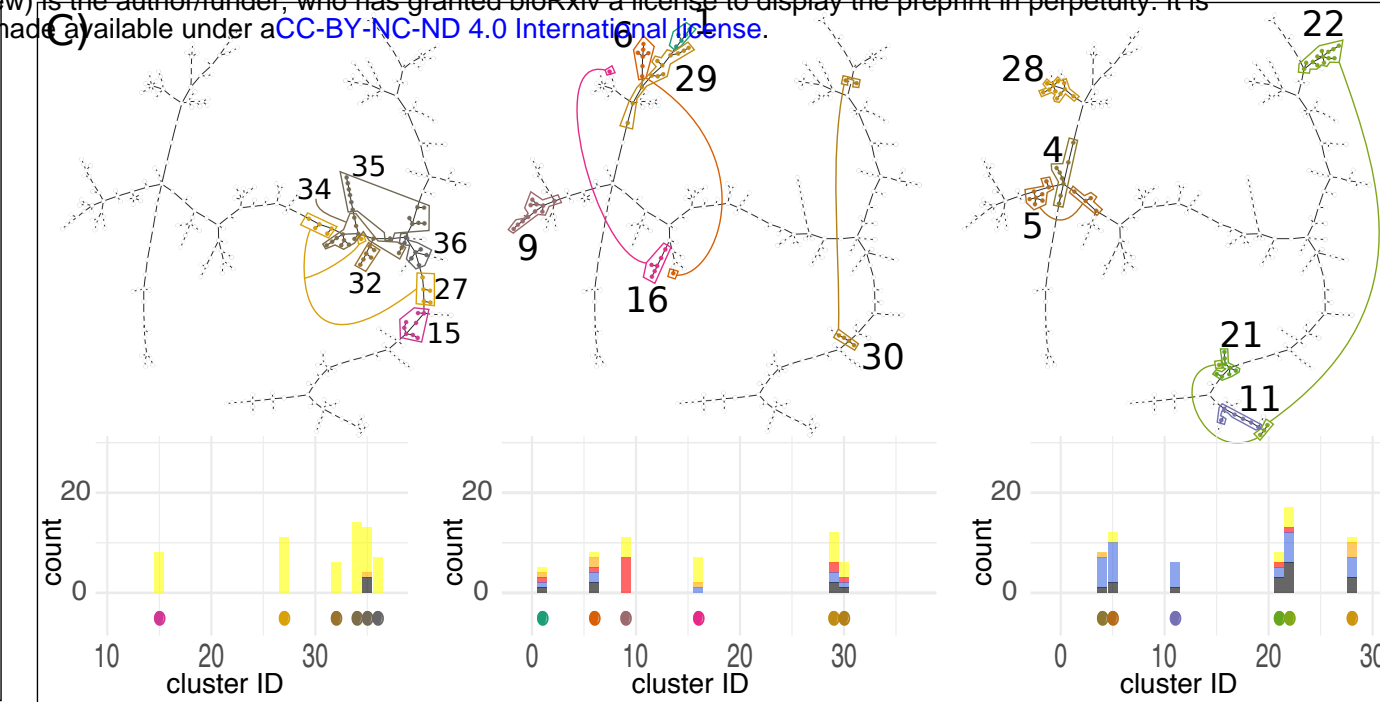

11

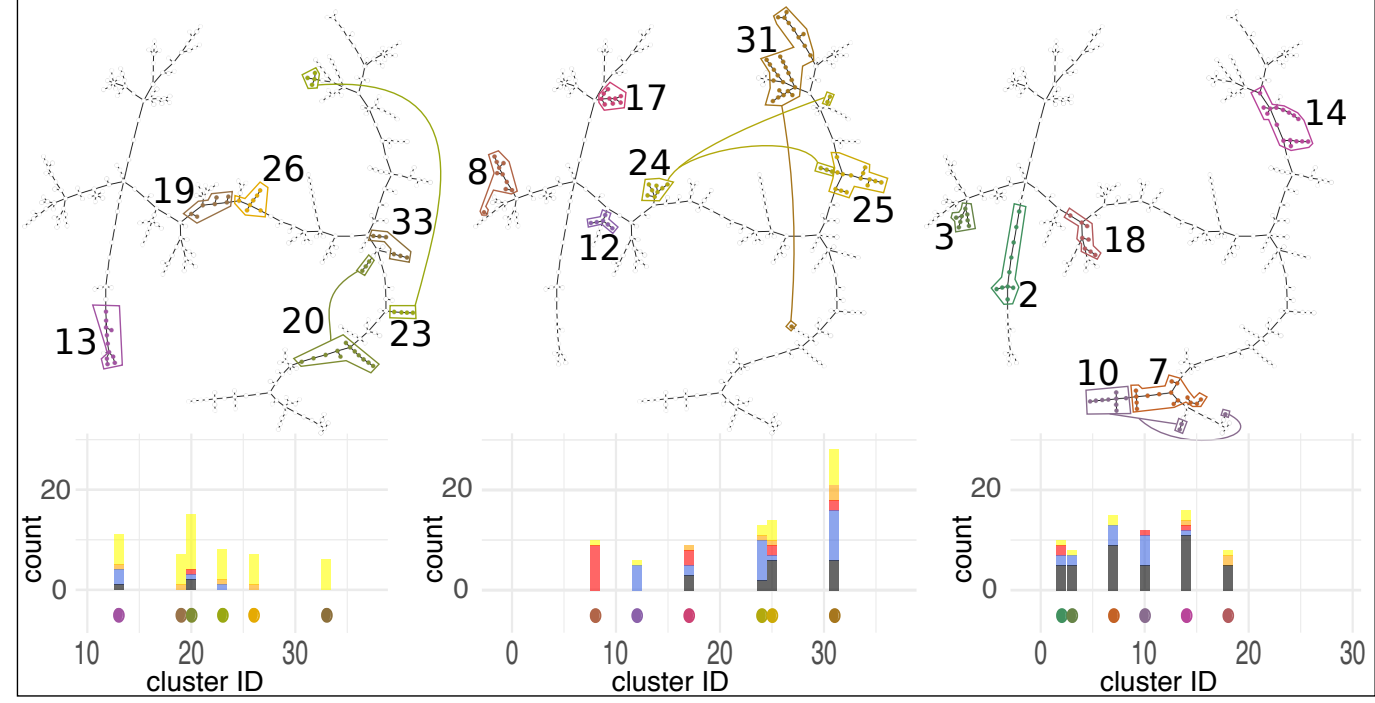

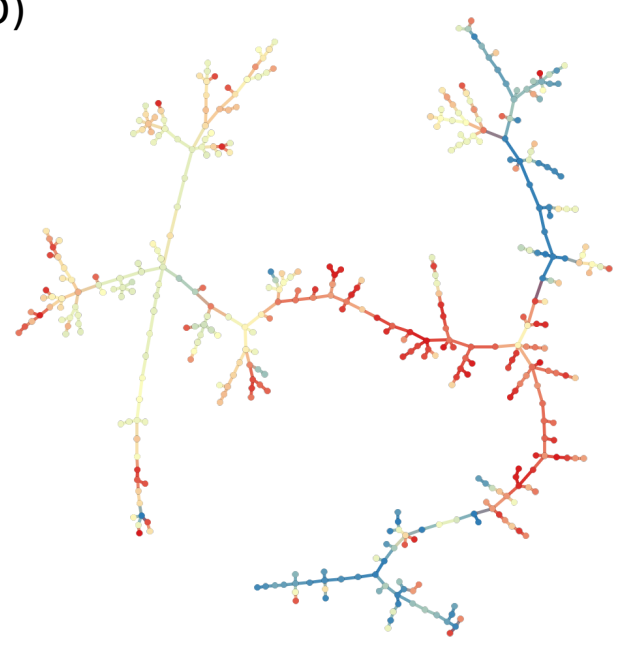

0.83 Temperature 29.31

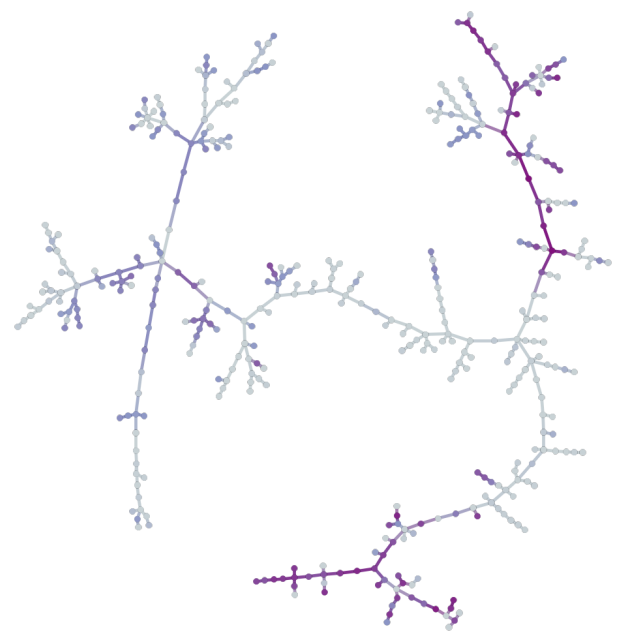

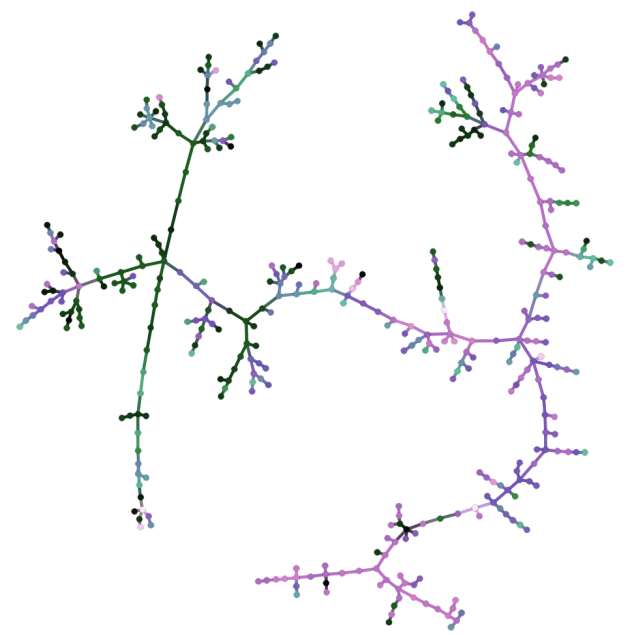

33.15

39.22
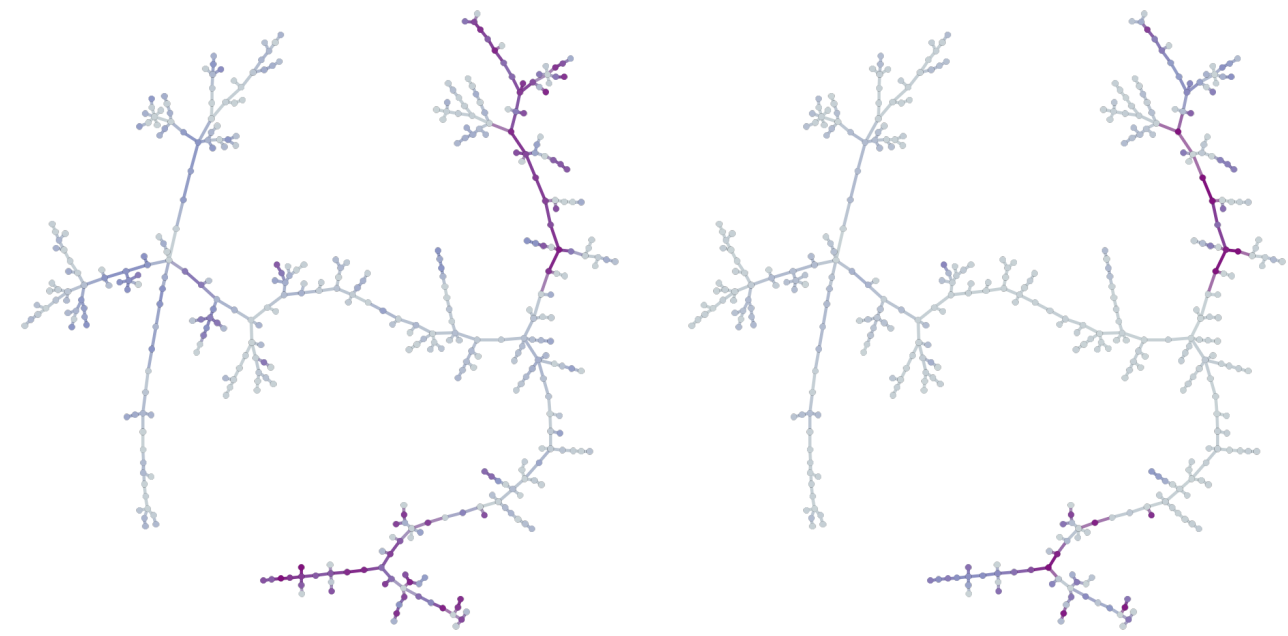

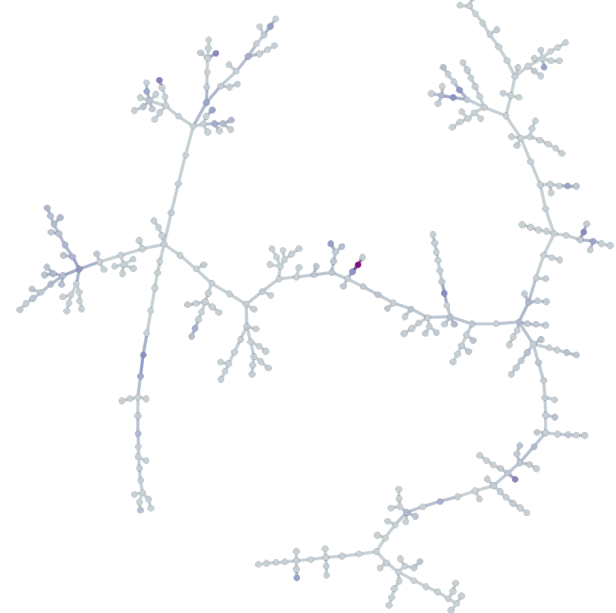

0 Fluorescence 3.51 